\title{
INTEGRAÇÃO DE DADOS ESPACIAIS EM SIG PARA AVALIAÇÃO DA SUSCEPTIBILIDADE À OCORRÊNCIA DE DESLIZAMENTOS
}

\author{
EusÉBIo ReIs ${ }^{1}$ \\ José Luís ZÊZERE ${ }^{2}$ \\ Gonçalo Teles Vieira ${ }^{3}$ \\ Maria Luísa Rodrigues ${ }^{4}$
}

\begin{abstract}
Resumo - A ocupação desajustada do território constitui um factor determinante na ocorrência e intensificação das catástrofes naturais, pelo que a identificação das áreas mais sensíveis ao desencadeamento destes fenómenos assume uma grande importância no ordenamento adequado das actividades humanas. O objectivo principal deste estudo, desenvolvido numa área a Norte de Lisboa, consiste na aplicação duma metodologia para a avaliação quantitativa da susceptibilidade à ocorrência de deslizamentos à escala regional. $\mathrm{O}$ modelo é baseado no uso de algoritmos que assentam na análise estatística e probabilística da relação entre os deslizamentos e os factores que os condicionam, em que são calculados os valores da função de favorabilidade para as classes de cada um desses factores. A integração dos dados espaciais é efectuada através da interpretação bayesiana da função de favorabilidade, obtendo-se uma hierarquização dos valores de susceptibilidade entre 0 e 1 . De forma a validar o modelo de predição, é aplicado um procedimento de validação cruzada utilizando-se uma partição espacial aleatória dos movimentos conhecidos.
\end{abstract}

Palavras-chave: Deslizamentos translacionais superficiais, Sistemas de Informação Geográfica, função de favorabilidade, probabilidade bayesiana, área de estudo de Trancão-Fanhões.

Abstract - Spatial data integration in GIS for LANDSlide susceptibility PREDICTION. Improper land use is an important factor for the occurrence and intensification of natural hazards. Therefore, a correct hazard zonation is of extreme significance for the adequate planning of human activities. The main objective of

1 Investigador do Centro de Estudos Geográficos e Assistente da Universidade de Lisboa. E-mail: ejmreis@mail.telepac.pt

2 Investigador do Centro de Estudos Geográficos e Professor Auxiliar da Universidade de Lisboa. E-mail: jlzezere@fl.ul.pt

3 Investigador do Centro de Estudos Geográficos e Assistente da Universidade de Lisboa. E-mail: gtvieira@fl.ul.pt

4 Investigadora do Centro de Estudos Geográficos e Professora Auxiliar da Universidade de Lisboa. E-mail: luisa.rodrigues@mail.telepac.pt 
this study, applied to a test site in the North of Lisbon (Fanhões-Trancão), is the application of a comprehensive methodology for landslide susceptibility evaluation at a regional scale. The methodological framework is supported by a relational database for GIS processing that includes maps of landslides and of conditioning factors (i.e. slope, aspect/geological structure, lithology, superficial deposits and land use). These maps were produced from detailed field surveys or derived from existing documents. Since the occurrence of distinct types of landslides is influenced differently by the conditioning factors, shallow translational landslides were chosen as an example for the application of the methodology. The susceptibility model is based on statistical and probabilistic algorithms that establish the relationships between the landslides and the conditioning factors (favourability functions), and allow the evaluation and validation of the map layers (independent variables) to be incorporated in the model. The spatial data integration in GIS environment is based in the bayesian interpretation of the favourability function, a technique that ranks the susceptibility values of landslide occurrence from 0 to 1 . For model evaluation, following a cross-validation procedure, a random sample of the shallow translational landslides was used.

Key words: Shallow translational landslides, Geographical Information Systems, favourability function, bayesian probabillity, Fanhões-Trancão test site.

Resumé - INTÉGRATION DE DONNÉES SPATIALES DANS UN GIS POUR LA PRÉDICTION DES RISQUES DE GLISSEMENT DE TERRAIN. L'occupation inadaptée du territoire est un facteur important d'apparition et d'intensification des catastrophes naturelles. L'identification des lieux les plus exposés à celles-ci est donc nécessaire à la réalisation d'un aménagement efficace des activités humaines. L'objet principal de la présente étude, qui porte sur un lieu situé au Nord de Lisbonne (Fanhões-Trancão), est de tester une méthode d'évaluation quantitative du risque de glissements de terrain, à l'échelle régionale. Le modèle utilisé comporte des cartes des glissements de terrain observés et de leurs facteurs conditionnants, basées sur des levées de terrain et sur les documents existants. Les glissements superficiels ont été choisis en exemple. Le modèle de "susceptibilité» est basé sur des algorithmes statistiques et probabilistiques qui décrivent les relations existant entre les glissements de terrainet leurs facteurs conditionnants (fonctions de «favorabilité») et qui permettent l'évaluation et la validation des thèmes cartographiques à incorporer dans le modèle. L'intégration de données spatiales dans un milieu SIG est basée sur l'interprétation bayesienne de la fonction de «favorabilité », une technique qui permet de classer de 0 à 1 les valeurs de «susceptibilité» d'apparition des glissements. Pour l'évaluation du modèle selon une technique de validation croisée, on a utilisé un échantillonnage aléatoire des glissements de terrain superficiels.

Mots-clés: Glissements de terrain superficiels, SIG, fonction de «favorabilité», probabilité bayesienne, Trancão-Fanhões.

\section{INTRODUÇÃO}

A ocupação de áreas sensíveis constitui um factor potenciador de catástrofes naturais. A análise de alguns destes fenómenos ocorridos recentemente na Europa permitiu concluir que a utilização desajustada do território tem constituído um factor determinante para a sua ocorrência ou agravamento (AyALA- 
CARCEDo, 2000) e, portanto, pode ser considerada responsável pelos prejuízos materiais e humanos daí decorrentes. No que se refere aos movimentos de vertente, a utilização incorrecta do território tem sido responsável pelo aumento da vulnerabilidade, contribuindo para o agravamento das consequências das catástrofes naturais (ZÊZERE, 1996; Luino, 1998). Deste modo, é essencial a identificação das áreas mais susceptíveis à ocorrência destes fenómenos, de forma a permitir um uso do território mais adequado e a diminuir o grau de vulnerabilidade associado às infra-estruturas humanas.

Nas últimas décadas têm sido feitas várias tentativas com vista à definição de áreas de perigosidade à escala regional, com base na utilização de métodos directos (geomorfológicos) e indirectos (quantitativos e semi-quantitativos) (Hansen, 1984; Hutchinson, 1995; Carrara et al., 1998). Ambas as abordagens são baseadas no princípio de que os factores que condicionaram a actividade dos deslizamentos já verificados serão igualmente responsáveis pela ocorrência de deslizamentos futuros. Assim, a distribuição espacial da susceptibilidade à ocorrência de deslizamentos pode ser estabelecida através do cruzamento da distribuição espacial dos movimentos de vertente conhecidos com os padrões espaciais dos factores condicionantes considerados relevantes para a explicação da instabilidade (CARRARA et al., 1998). A utilização de Sistemas de Informação Geográfica (SIG) tem possibilitado o desenvolvimento de modelos de avaliação da susceptibilidade cada vez mais complexos, baseados em métodos quantitativos, pois permite o cruzamento de um grande número de temas cartográficos e a análise estatística da relação entre os deslizamentos conhecidos e as variáveis independentes espacializadas.

A avaliação da capacidade de predição dos movimentos de vertente futuros deve ser obtida através da validação dos mapas de susceptibilidade à ocorrência de deslizamentos. No entanto, tal como foi referido por Guzzetri et al. (1999), estritamente falando, a validação da predição de deslizamentos futuros não é possível. Apesar desta limitação, têm sido efectuadas algumas tentativas para medir a adequação dos modelos preditivos à susceptibilidade de ocorrência de deslizamentos (Yin e YAN, 1988; CARRARA et al., 1995; IrIGARAY et al., 1996; ZêZERE, 2002). Porém, a maior parte destes estudos não fornece uma validação da predição mas sim uma taxa de sucesso, pois o mesmo conjunto de deslizamentos que foi usado para construir a análise de predição foi também usado para validar os modelos de susceptibilidade. Esta situação deve-se à grande dificuldade em obter dados fiáveis da ocorrência dos deslizamentos ao longo do tempo, pelo que, na ausência da componente temporal, apenas é possível obter uma hierarquia da susceptibilidade das unidades de terreno.

O objectivo deste estudo consiste na aplicação duma metodologia para a avaliação quantitativa da susceptibilidade à ocorrência de deslizamentos à escala regional através da integração de dados espaciais no âmbito de um SIG. O modelo de susceptibilidade é baseado em algoritmos que assentam na análise estatística/probabilística, mais concretamente na comparação entre as unidades de terreno correspondentes a deslizamentos conhecidos e as correspondentes às 
características das vertentes. Para validar o modelo de predição da ocorrência de deslizamentos é aplicado um procedimento de validação cruzada, usando uma partição espacial aleatória dos movimentos ocorridos no passado.

Para a execução da metodologia proposta foi necessário concretizar quatro etapas essenciais:

- a construção duma base de dados relacional para processamento em SIG;

- a análise estatística de forma a estabelecer a relação entre os atributos dos deslizamentos e validar o conjunto de temas cartográficos (variáveis independentes) a utilizar no modelo;

— o uso de funções de favorabilidade para integração dos dados espaciais, neste caso baseada na probabilidade bayesiana, apoiada num SIG, para a obtenção de mapas de susceptibilidade à ocorrência de deslizamentos;

- a avaliação quantitativa dos resultados obtidos, de forma a validar o modelo de predição.

\section{ENQUADRAMENTO E DESCRIÇÃO GERAL DA ÁREA DE ESTUDO}

A área de estudo de Fanhões-Trancão, com $9,47 \mathrm{~km}^{2}$, situa-se na região a Norte de Lisboa, no sector intermédio da bacia hidrográfica do rio Trancão. Insere-se na bacia sedimentar meso-cenozóica portuguesa e está localizada logo a norte do contacto entre esta unidade morfoestrutural e a planície aluvial do Tejo (fig. 1).

A estrutura geológica da região em que se insere a área de estudo, embora complicada por deformações anticlinais e sinclinais locais, é marcada por uma inclinação moderada $\left(12^{\circ}\right)$ dos estratos para Sul e Sudeste em direcção ao estuário do Tejo. A esta estrutura monoclinal, alia-se a alternância de rochas de diferente dureza, permeabilidade e plasticidade, tais como arenitos, margas, calcários, calcários margosos, basaltos e tufos vulcânicos. Estas características permitiram, durante o Quaternário, o desenvolvimento de costeiras e de bacias quase fechadas. Entre as primeiras destacam-se a de Lousa-Bucelas, situada no sector Norte e Nordeste da área amostra, e a de Odivelas-Vialonga, já fora da área de estudo (fig. 1). A área de estudo é parte integrante do reverso da costeira de Lousa-Bucelas, uma extensa vertente subestrutural definida por uma concordância geral entre a superfície topográfica e a inclinação geral dos estratos. Os afloramentos margosos, com intercalações de calcários e de calcários margosos, criam cornijas duplas secundárias nas vertentes mais declivosas; por outro lado, os calcários compactos sobressaem claramente na paisagem como importantes cornijas.

A existência de uma deformação tectónica positiva em relação à bacia do Tejo constitui um factor de grande significado no desenvolvimento das principais unidades morfológicas regionais. O levantamento geral permite compreender o escalonamento de vários níveis de erosão e os vigorosos entalhes dos cursos de água, responsáveis pelas vertentes íngremes, apesar da altitude variar apenas 
entre 20 e 316 metros na área de estudo. Esta inclui dois vales cataclinais de orientação geral Norte-Sul: o vale do rio Fanhões, no lado Oeste, e o vale encaixado do rio Trancão, no lado Leste, que corta profundamente o relevo monoclinal (figs. 1 e 2).

\section{OS DESLIZAMENTOS E OS FACTORES CONDICIONANTES}

A larga maioria dos deslizamentos recentes verificados na região de Lisboa denuncia uma claro sinal climático, sendo sensível a restrição da actividade geomorfológica a anos bastante chuvosos ou, pelo menos, marcados por episó-

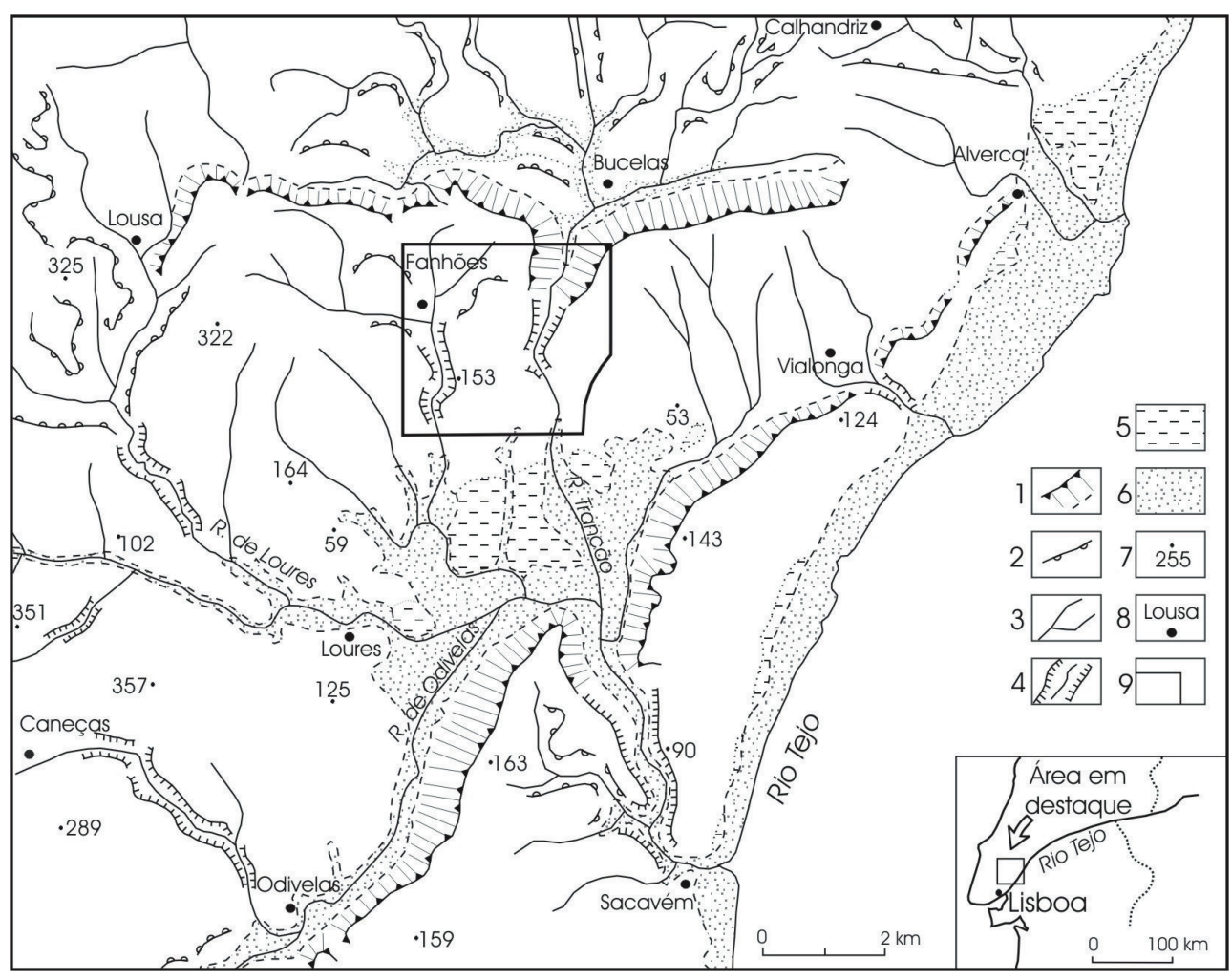

Fig. 1 - Esboço morfológico simplificado da área a Norte de Lisboa (adaptado de FERREIra et al., 1987: 228) e localização da área de estudo de Fanhões-Trancão. 1. Frente de costeira (Lousa-Bucelas e Odivelas-Vialonga); 2. Outras vertentes com cornijas; 3. Curso de água; 4. Garganta; 5. Terraço fluvial; 6. Planície aluvial; 7. Altitude em metros; 8. Povoação e 9. Área de estudo de Fanhões-Trancão (fig. 2). Fig. 1 - Schematic morphological map of the Area North of Lisbon (adapted from FERREIRA et al., 1987: 228) and location of the Fanhões-Trancão test site. 1. Front slope of cuesta; 2. Other cliff; 3. Stream; 4. Gorge; 5. Fluvial terrace; 6. Alluvial plain; 7. Elevation in meters; 8. Town and 9. Fanhões-Trancão test site (fig. 2). 


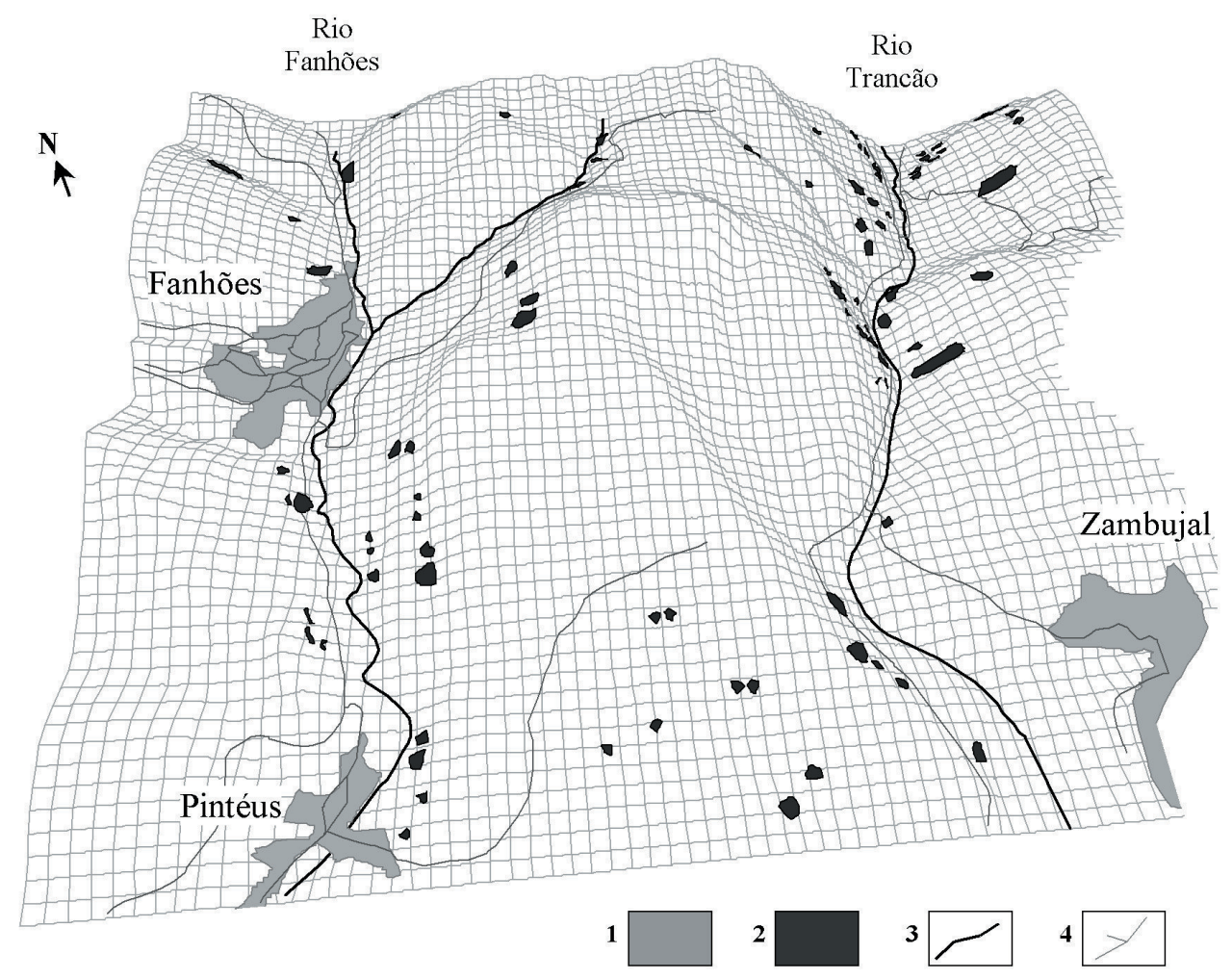

Fig. 2 - Área de estudo de Fanhões-Trancão (a escala varia com a perspectiva). 1. Núcleos urbanos; 2. Deslizamentos translacionais superficiais; 3. Cursos de água principais e 4. Estradas.

Fig. 2 - Fanhões-Trancão test site (scale varies with the perspective). 1. Urban areas; 2 . Superficial translational landslides;

3. Main streams and 4. Roads.

dios de precipitação muito intensa (ZêZERE, 1996). Deste modo, na área de Fanhões-Trancão, o estado de actividade dos deslizamentos está mais directamente relacionado com o período de retorno da precipitação que os torna activos, do que com as suas características mecânicas e dinâmicas. A precipitação constitui, assim, o motor que desencadeia os deslizamentos, tendo um papel essencial na sua frequência. Os chamados factores do terreno explicam a forma como se distribuem espacialmente no território.

Os estudos efectuados na região a Norte de Lisboa têm concluído que os mesmos factores condicionam de forma distinta a ocorrência de diferentes tipos de deslizamentos (Zêzere, 1996; 2002). Deste modo, foi efectuada a sua separação e o modelo foi aplicado separadamente para cada tipo de deslizamento. No presente artigo, para exemplificação da metodologia utilizada, são apenas utilizados os deslizamentos translacionais superficiais. 
Foram inicialmente consideradas as seguintes variáveis como factores condicionantes para a predição da susceptibilidade à ocorrência de deslizamentos: declive e exposição das vertentes, geologia, depósitos superficiais, uso do solo, distância a estradas e distância aos cursos de água. No entanto, estes dois últimos factores, embora utilizados numa primeira fase do processo de modelação, foram retirados do modelo final. Os mapas relativos a estes dois temas foram classificados de acordo com a distância às entidades lineares (mapas de distâncias) e integrados na base de dados geral. Normalmente, estes factores possuem uma influência muito específica na ocorrência de deslizamentos, afectando áreas muito restritas com características particulares. $\mathrm{Na}$ área de estudo, a maior parte da ocorrência de deslizamentos é claramente condicionada por outras variáveis, e a sua distribuição reflecte a influência mais forte destes temas, pois a maior parte dos deslizamentos ocorre em áreas afastadas das estradas e dos cursos de água. Visto que o modelo usado para a predição é baseado em densidades, as áreas finais resultam com maiores probabilidades quando aquelas áreas estão localizadas a distâncias maiores destas entidades. Deste modo, a ocorrência de deslizamentos que se situam próximos das estradas e dos cursos de água não é devidamente prevista, pelo que estas duas variáveis foram retiradas do modelo.

A exposição das vertentes na área de estudo forneceu, de forma indirecta, uma informação morfoestrutural relevante. De facto, o controlo estrutural na morfologia da área pôs em evidência a importância deste mapa, visto que as áreas de exposição Sul e Sudeste são aquelas em que a inclinação das camadas geológicas é similar à exposição das vertentes (vertentes cataclinais). Sectores com orientação Norte e Noroeste reflectem áreas onde a exposição é oposta à da inclinação das camadas geológicas (vertentes anaclinais). Deste modo, o tema da exposição permite avaliar o controlo estrutural na instabilidade das vertentes na área estudada.

\section{A CONSTRUÇÃO DA BASE DE DADOS}

Os diversos temas cartográficos podem ser divididos em dois grupos: o que representa a distribuição dos deslizamentos translacionais superficiais na área de amostra, que constitui, assim, a variável dependente no modelo; e os que representam as variáveis independentes, com algum tipo de influência na ocorrência dos deslizamentos. É a partir destes ficheiros iniciais que são construídos os restantes temas cartográficos durante os diversos processos de modelação, até à geração dos mapas finais que representam o zonamento da susceptibilidade à ocorrência dos deslizamentos.

Quase todo o processo de criação de base de dados foi desenvolvido em ambiente do software SIG ILwis 2.1, em estrutura vectorial, e seguiu os procedimentos comuns de digitalização, georreferenciação, vectorização e inserção de atributos. A excepção refere-se aos dados altimétricos, cuja vectorização 
das curvas de nível e pontos cotados foi efectuada no CAD MicroStation 95 e, posteriormente, importada para ambiente ILwis. Mais tarde, todos os dados espaciais foram convertidos para estrutura matricial, de forma a poder efectuar as diversas fases da modelação em ILwis 2.1. A resolução utilizada é de $5 \mathrm{~m}$ (células com $25 \mathrm{~m}^{2}$ ), considerada adequada às características da informação de base e aos objectivos em vista.

\section{A aquisição de dados espaciais}

A construção da base de dados cartográfica, que engloba os vários mapas utilizados para a avaliação da susceptibilidade à ocorrência de deslizamentos, foi baseada em duas tarefas principais complementares: a digitalização e edição da informação cartográfica original e o levantamento de campo detalhado (fig. 3 e Quadro 1). O trabalho de campo centrou-se em dois objectivos: por um lado, fazer a verificação da distribuição dos afloramentos litológicos, das

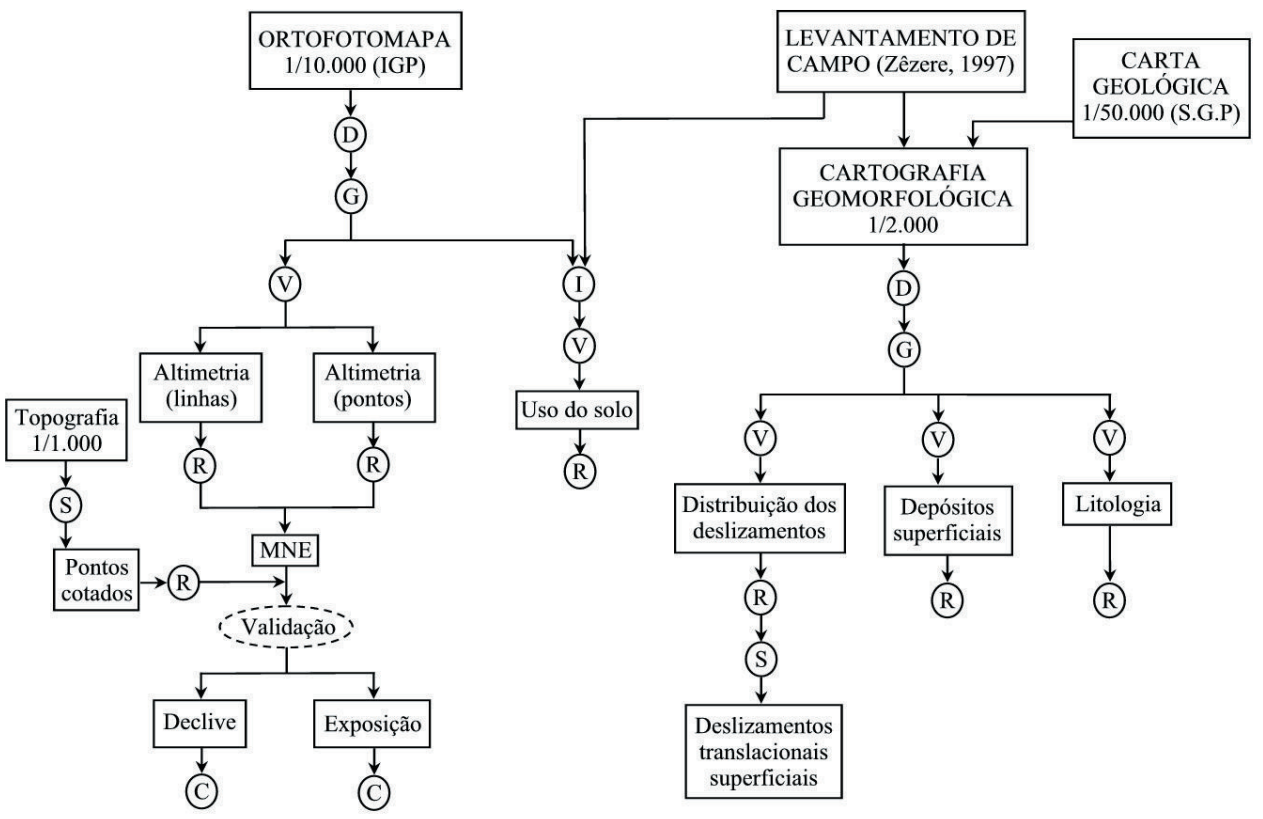

Fig. 3 - Sequência de procedimentos para a construção da base de dados em SIG com vista à modelação da susceptibilidade à ocorrência de deslizamentos

(D: digitalização; G: georreferenciação; I: interpretação; V: vectorização;

S: selecção de atributos ou objectos; R: rasterização e C: classificação).

Fig. 3 - The process steps in the digital database construction for modelling superficial translational landslides assessment (D: digitalisation; G: georreferencing; I: interpretation; V: vectorization; S: selection of attributes or objects; $R$ : rasterization and C: classification). 
manchas de ocupação do solo e dos depósitos superficiais, de forma a corrigir e complementar a informação dos elementos cartográficos e tornar estes dados compatíveis com a escala de trabalho; por outro lado, fazer o inventário e cartografia da distribuição dos diversos tipos de deslizamentos.

Quadro 1 - Características dos dados espaciais e processos associados à criação da base de dados.

Table 1 - Spatial data features and database construction processes.

\begin{tabular}{|c|c|c|c|c|c|c|}
\hline $\begin{array}{c}\text { Informação } \\
\text { de base }\end{array}$ & Produtor & $\begin{array}{c}\text { Escala } \\
\text { original }\end{array}$ & Processos & $\begin{array}{c}\text { Objectos } \\
\text { (vectores) }\end{array}$ & $\begin{array}{l}\text { Temas } \\
\text { criados }\end{array}$ & Atributos \\
\hline \multirow{3}{*}{$\begin{array}{l}\text { Ortofotomapa, } \\
\text { folha } 110 / 210 \\
\text { (1990) }\end{array}$} & \multirow{3}{*}{ IGP } & \multirow{4}{*}{$1 / 10000$} & \multirow{7}{*}{$\begin{array}{c}\text { Digitalização } \\
\downarrow \\
\text { Georreferenciação } \\
\downarrow \\
\text { Vectorização } \\
\downarrow \\
\text { Inserção de } \\
\text { atributos }\end{array}$} & linhas & Curvas de nível & \multirow{2}{*}{ Altitude } \\
\hline & & & & pontos & Pontos cotados & \\
\hline & & & & \multirow{5}{*}{ polígonos } & \multirow{2}{*}{ Uso do solo } & \multirow{2}{*}{$\begin{array}{l}\text { Classes de } \\
\text { uso do solo }\end{array}$} \\
\hline \multirow{3}{*}{$\begin{array}{c}\text { Levantamento } \\
\text { de campo }\end{array}$} & \multirow{3}{*}{$\begin{array}{l}\text { ZÊZERE, } \\
1997\end{array}$} & & & & & \\
\hline & & \multirow[t]{2}{*}{$1 / 2000$} & & & Depósitos & $\begin{array}{c}\text { Tipos } \\
\text { e espessura }\end{array}$ \\
\hline & & & & & Deslizamentos & Tipos \\
\hline $\begin{array}{c}\text { Carta Geológica } \\
\text { de Portugal, } \\
\text { folha 34-B }\end{array}$ & $\begin{array}{l}\mathrm{SGP} / \\
/ \mathrm{IGM}\end{array}$ & $\begin{array}{l}1 / 10000 \\
1 / 50000\end{array}$ & & & Litologia & $\begin{array}{l}\text { Tipos } \\
\text { litológicos }\end{array}$ \\
\hline
\end{tabular}

O uso de dados de deslizamentos a partir de um levantamento de campo muito detalhado na modelação em SIG exige dados fiáveis provenientes dos outros temas cartográficos, de forma a manter a coerência na utilização conjunta da informação no modelo. Deste modo, a criação dos restantes temas cartográficos da base de dados obedeceu a um conjunto de procedimentos, que passaram pela verificação através do trabalho de campo e pela avaliação da qualidade do modelo numérico de elevação.

\section{Os deslizamentos translacionais superficiais}

A cartografia geomorfológica detalhada constituiu a principal metodologia usada para o estudo dos movimentos de vertente na área de estudo. Esta foi sistematicamente executada no campo na escala 1:2 000 (ZÊZERE, 1997) e posteriormente convertida para 1:10000. O levantamento sistemático dos deslizamentos tornou possível a construção de uma base de dados com a distribuição espacial de 132 movimentos de vertente. O tema com os movimentos de vertente foi digitalizado a partir do mapa geomorfológico na escala 1:10 000. A cada movimento foi atribuído um único identificador, que foi utilizado para efectuar a ligação a uma base de dados onde estão presentes diversos atributos específicos, nomeadamente o tipo de deslizamento. 


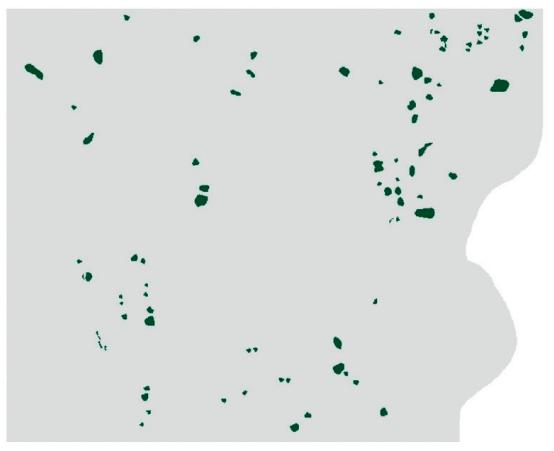

A - Deslizamentos / Landslides

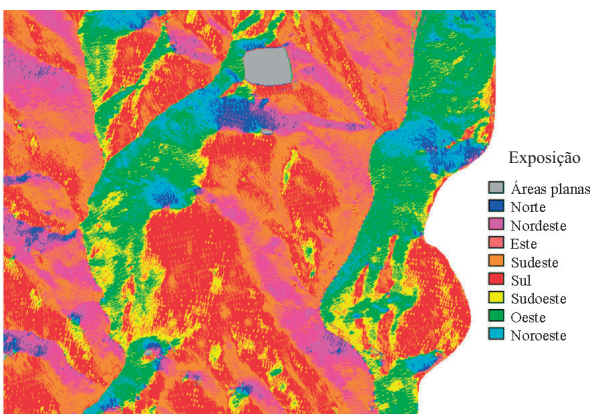

C - Exposição das vertentes / Aspect

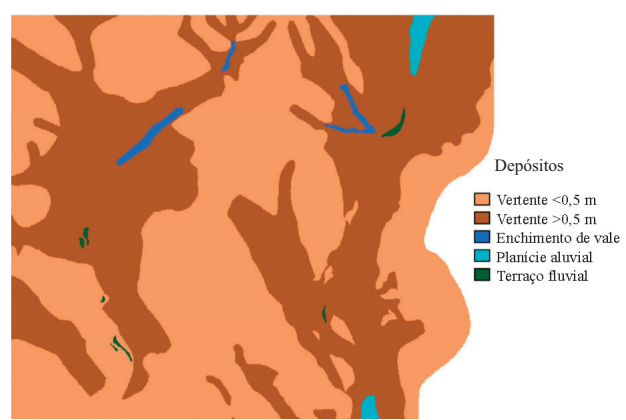

E - Depósitos superficiais / Superficial deposits

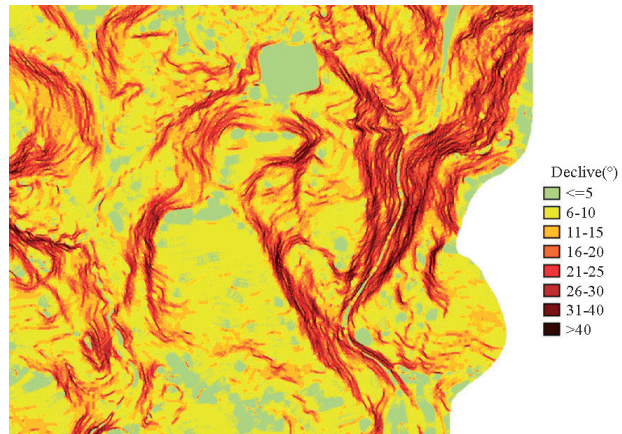

B - Declive / Slope angle

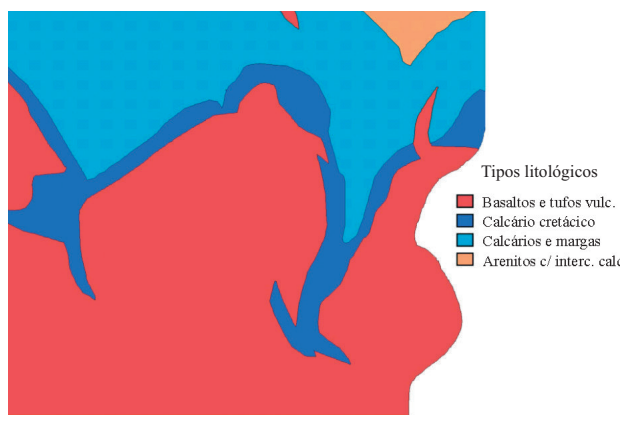

D - Litologia / Lithology

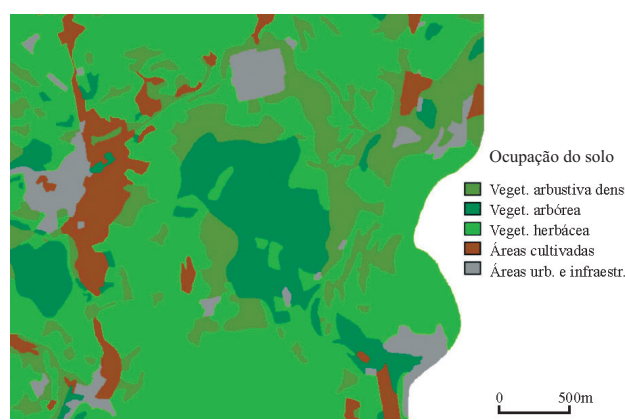

F - Ocupação do solo / Land use

Fig. 4 - Distribuição espacial dos deslizamentos translacionais superficiais (A) e das classes dos factores condicionantes (B, C, D, E e F) na área de estudo de Fanhões-Trancão.

Fig. 4 - Spatial distribution of superficial translational landslides $(A)$ and conditioning factor cathegories ( $B, C, D, E$ and $F$ ) in the Fanhões-Trancão test site. 
Neste trabalho, como já foi referido, são utilizados apenas os deslizamentos translacionais superficiais (figs. 2 e 4A). Seleccionaram-se, assim, 87 eventos que somam uma área total instabilizada de $132875 \mathrm{~m}^{2}$ (apenas $0,014 \%$ da superfície total). A dimensão dos deslizamentos varia entre 150 e $7900 \mathrm{~m}^{2}$, e a respectiva densidade é 9,2 eventos $/ \mathrm{km}^{2}$.

\section{Modelo numérico de elevação}

O modelo numérico de elevação (MNE) é um dos mais importantes temas para o processo de análise de susceptibilidade visto que é usado para produzir temas derivados com bastante significado, tais como os mapas de declive e de exposição, que se verificou serem factores condicionantes para a actividade dos deslizamentos. A informação da altitude foi obtida a partir da digitalização e vectorização das curvas de nível, com equidistância de $5 \mathrm{~m}$, e pontos cotados, com precisão de $0,5 \mathrm{~m}$, do ortofotomapa 1/10 000 (Instituto Geográfico Português - IGP, folha 110/210 - S. Julião do Tojal, 1990) da área de estudo. Os dados lineares e pontuais foram posteriormente convertidos para estrutura matricial, e, após a sua junção num mesmo ficheiro, foi gerado o MNE com base na interpolação linear das células com valores conhecidos.

Como tem sido posto em evidência por diversos autores (SPanner, 1983; Franklin et al., 1986; Mason et al., 1988; Moellering e Kimerling, 1990; QuinN et al., 1991; e Green, 1992, citados por Bolstad e Stowe, 1994), o rigor de um MNE é de importância crucial, pois os erros na base de dados terão influência directa nos produtos dele derivados e serão propagados através das análises espaciais. Isto é particularmente verdadeiro na classificação ou outras aplicações de modelação cartográfica onde a elevação, declive e exposição são derivados a partir dos MNE e usados com outros dados espaciais. Quando os erros no MNE forem considerados elevados, a sua origem deve ser encontrada de forma a produzir um modelo mais rigoroso (i.e., através de nova georreferenciação, eliminação de incorrecções locais, modificação do método de interpolação, etc.). A verificação do rigor do MNE foi efectuada utilizando como dados de referência os valores dos pontos cotados obtidos a partir de um mapa topográfico detalhado na escala 1:1 $000^{5}$, de acordo com a metodologia de MoncKтon (1973). De forma a evitar desfasamentos provocados por alterações artificiais da topografia entre as datas dos dois documentos (1990 e 1993), procedeu-se previamente à remoção dos pontos cotados associados a áreas em que houve modificações de terreno induzidas pelo Homem (especialmente trabalhos recentes em pedreiras e construção de estradas), para uma mais realística determinação do erro. Os valores de referência cobrem assim toda a área de estudo e representam as diversas características morfológicas (diferentes altitudes, diferentes formas e diferentes declives).

5 Base cartográfica digital, de 1993, gentilmente cedida pela Câmara Municipal de Loures. 
Através da sobreposição do MNE e do tema, que contém os pontos de referência da altitude, foram obtidas as diferenças de altitude e foi produzido um mapa pontual para interpretação visual. Para a avaliação quantitativa do erro, calcularam-se o desvio padrão, a média, o máximo e o erro quadrático médio (EQM). A significância de erros entre -2 e $1 \mathrm{~m}$ com $70,3 \%$ dos pontos verificados, juntamente com os valores dos outros índices, suporta um bom grau de rigor do MNE, considerando os objectivos propostos.

\section{Os temas correspondentes aos factores condicionantes}

\section{Declive e exposição das vertentes}

Os temas do declive e da exposição das vertentes foram construídos directamente a partir do MNE. Para a integração no modelo de susceptibilidade, o declive foi classificado seguindo a proposta prévia de ZêZERE (1997), com a adição das classes de $30-40^{\circ}$ e $>40^{\circ}$ (fig. 4B), que mostrou bons resultados para a região a Norte de Lisboa, onde se inclui a área de Fanhões-Trancão.

A informação da exposição das vertentes, que reflecte em grande parte a morfoestrutura da área de estudo, foi classificada em oito orientações, para além das áreas planas (fig. 4C).

\section{Litologia}

A informação geológica e litológica foi obtida a partir da Carta Geológica de Portugal, na escala 1:50 000 (folha 34-B - Loures), dos Serviços Geológicos de Portugal/Instituto Geológico e Mineiro (SGP/IGM), e da verificação dos limites dos afloramentos no terreno à escala 1:2 000. Os principais complexos litológicos estão representados (fig. 4D) e incluem: arenitos, que aparecem no sector norte do vale do rio Trancão; afloramentos essencialmente margosos, com intercalações de calcários e de calcários margosos; calcários com rudistas; por fim, o Complexo Vulcânico de Lisboa, cujas rochas vulcânicas apresentam uma grande diversidade litológica (basaltos compactos, basaltos muito alterados e tufos vulcânicos). A informação resultante foi posteriormente generalizada para a escala 1:10 000, tendo-se procedido à sua digitalização, georreferenciação e vectorização.

\section{Depósitos superficiais}

Os depósitos superficiais representam um dos mais importantes temas, especialmente no que diz respeito aos deslizamentos translacionais superficiais. Este tema foi produzido a partir da digitalização de um levantamento de campo muito detalhado na escala 1:2 000 (ZêzERE, 1997) e posteriormente transferido para um mapa geomorfológico à escala 1:10 000. Foi dada especial atenção à profundidade dos depósitos superficiais, visto que parece constituir um factor condicionante importante. Uma estimativa da profundidade dos depósitos foi 
efectuada no campo e o limite considerado foi de 0,5m (fig. 4E). Outros depósitos, que não de vertente, foram igualmente cartografados mas a sua extensão não é significativa.

\section{Uso do solo}

O mapa do uso do solo foi baseado na interpretação do ortofotomapa 1/10 000 (IGP, folha 110/210, 1990), complementada com o respectivo trabalho de campo. Foram individualizadas cinco classes de uso do solo de acordo com características que permitem uma diferenciação no controlo da actividade dos deslizamentos na área. Os elementos principais foram o tamanho e a densidade da cobertura de vegetação (essencialmente tendo em consideração o efeito estabilizador das raízes) e as áreas urbanas e de intervenção humana, em geral densamente construídas e geralmente mais estáveis no que diz respeito à actividade dos deslizamentos na área. A vegetação foi classificada em áreas cultivadas (plantas de tamanho reduzido, vinhas, etc.), arbustos densos (geralmente arbustos pequenos e médios muito densos num típico ecossistema mediterrâneo secundário degradado), vegetação herbácea (correspondendo geralmente a áreas abandonadas que foram antes cultivadas), e árvores (cobertura arbórea não necessariamente densa, sem chegar a constituir floresta) (fig. 4F).

\section{A INTEGRAÇÃO DE DADOS ESPACIAIS}

\section{O problema da integração de dados espaciais}

Uma das dificuldades no desenvolvimento de processos de modelação em SIG consiste na utilização conjunta da informação espacial, que, na generalidade dos casos, combina diferentes temas cartográficos que constituem, frequentemente, dados de diferentes tipos. Em suporte digital, a realidade pode ser representada de várias formas, a que estão associados diferentes tipos de valores. No caso concreto da informação de partida utilizada neste estudo, deparamo-nos com as seguintes situações:

- elementos discretos com valores nominais (linhas): rede hidrográfica e rede viária;

- elementos discretos com valores racionais: pontos cotados (pontos) e curvas de nível (linhas);

— informação contínua com valores nominais (polígonos): litologia, depósitos superficiais e ocupação do solo;

- informação discreta com valores nominais (polígonos): tipo de deslizamentos.

Para a aplicação da metodologia desenvolvida neste trabalho, são exigidas duas condições essenciais: todas as variáveis devem ser contínuas, ou seja, 
cobrir a totalidade da área estudada; e o valor associado a cada uma delas deverá ser interpretado como informação nominal. A primeira condição permite que toda a área estudada seja abrangida, visto que a existência de lacunas espaciais para uma variável implica a inexistência de resultados finais nessa área; a segunda condição permite que toda a informação de natureza diversa (declives, ocupação do solo, depósitos superficiais, etc.) seja tratada a um mesmo nível e usada em conjunto, de acordo com um determinado método de integração. Para cumprir estas condições, são quatro as situações que devem ser tidas em conta:

- rede hidrográfica e rede viária: cálculo da distância às entidades geográficas (ribeiras e estradas) e posterior classificação dos dados de acordo com valores de distância pré-definidos;

— informação altimétrica (pontos cotados e curvas de nível): interpolação dos valores conhecidos, com a criação de um modelo numérico de elevação (MNE), e cálculo dos declives e exposições das vertentes, a que se segue a sua classificação de acordo com limites de classe pré-definidos;

- deslizamentos translacionais superficiais: classificação do tema cartográfico de acordo com a presença (1) ou a ausência (0) deste tipo de eventos;

- dados contínuos nominais (depósitos superficiais, litologia e ocupação do solo): não necessitam de qualquer tipo de transformação, pois as suas propriedades iniciais já correspondem às condições exigidas para a integração dos dados.

Deste modo, nos dois primeiros casos, os elementos discretos, que possuem dados nominais ou de razão, são transformados em informação contínua com valores racionais, que, por sua vez, dá origem a informação contínua nominal. Assim, cada tema cartográfico independente é constituído por um conjunto de classes ou categorias, as quais dividem o espaço de estudo, não são coincidentes entre si e possuem probabilidades de ocorrência superiores a zero na área de estudo.

\section{A função de favorabilidade}

Como forma de ultrapassar os problemas da combinação de dados espaciais heterogéneos, CHUng e FABBRI (1993) propuseram uma abordagem que designaram por função de favorabilidade (favourability function). Esta baseia-se no pressuposto de que a probabilidade de ocorrência de deslizamentos pode ser medida através das relações estatísticas bivariadas entre os deslizamentos conhecidos de um determinado tipo e os vários conjuntos específicos de dados espaciais, identificados como factores de instabilidade. É assim assumido que qualquer deslizamento ocorre sob condições particulares, traduzidas pelos valores dos factores condicionantes, as quais podem ser caracterizadas por esses conjuntos de dados espaciais. 
Tenha-se como referência uma área de estudo $\Phi$ e cada uma das unidades de terreno $\varphi$ que a constituem. Pretende-se conhecer a probabilidade de ocorrência de um tipo específico de evento espacial $\varepsilon$, neste caso deslizamentos translacionais superficiais, para uma área $\Phi$ tendo como base um conjunto de $n$ temas cartográficos $T_{i}(i=1,2, \ldots, n)$, definidos como factores explicativos. Para uma unidade de terreno $\varphi \mathrm{em} \Phi$, pode ser expressa a seguinte preposição

$\mathrm{P}_{\varphi}: « \varphi$ contém o evento $\varepsilon »$ ou « $\varphi$ está contido num objecto do tipo $\varepsilon »$.

Numa estrutura de dados matricial, como é o caso, a unidade de terreno $\varphi$ corresponde a cada uma das células (ou pixels) que compóem a matriz. Para cada tema $T_{i}$ o valor em cada célula $\varphi$ pode estar compreendido num intervalo $\left[\max _{i}, \min _{i}\right]$, no caso de medidas contínuas, ou num valor inteiro $\left\{1,2,3, \ldots \mathrm{n}_{i}\right\}$, no caso de medidas não contínuas. As $n$ camadas de dados cartográficos para cada localização $\varphi$ em $\Phi$ podem ser representadas duma forma quantificada por $n_{i}$, e podem ser expressas em função de $\Phi$ como $v_{i}$ (Eq. 1a).

Para integrar os diferentes temas cartográficos e comparar categorias dentro do mesmo tema ou entre temas, é calculada a função de favorabilidade relativa $r_{i}$. Este índice transforma os dados de cada tema $T_{i}$ num intervalo $[\alpha, \beta]$, que pode ser interpretado como uma medida de confiança (por exemplo, probabilidade) de que a preposição $\mathrm{P}_{\varphi}$ é verdadeira, dada a evidência em $\varphi$ no tema $T_{i}$, de acordo com uma determinada interpretação escolhida (Eq. 1b). Cada classe contínua ou de intervalo é transformada num valor de favorabilidade, variando entre limites constantes ( 0 e 1 , no caso da probabilidade).

Finalmente, obtém-se a função de favorabilidade $f_{i}$ que é a função composta $f_{i}(\varphi)=r_{i}(n(\varphi))$, para cada $\varphi$ incluído em $\Phi($ Eq. 1c).

a

$v_{i}:\left\{\begin{array}{l}T_{i} \rightarrow\left[\min _{i}, \text { max }_{i}\right] \\ T_{i} \rightarrow\left\{1,2,3, \ldots n_{i}\right\}\end{array} \rightarrow r_{i}:\left\{\begin{array}{l}{\left[\min _{i}, \max _{i}\right] \rightarrow[\alpha, \beta]} \\ \left\{1,2,3, \ldots n_{i}\right\} \rightarrow[\alpha, \beta]\end{array} \rightarrow f_{i}:\left\{\begin{array}{l}T_{i} \rightarrow\left[\min _{i}, \max _{i}\right] \rightarrow[\alpha, \beta] \\ T_{i} \rightarrow\left\{1,2,3, \ldots n_{i}\right\} \rightarrow[\alpha, \beta]\end{array}\right.\right.\right.$

Os temas cartográficos obtidos através das transformações anteriores quantificam o grau de segurança de uma preposição ser verdadeira à partida. Para cada unidade de terreno $\varphi$, correspondente neste caso a cada célula, temos $f_{1}(\varphi), f_{2}(\varphi), \ldots f_{n}(\varphi)$, que suporta o grau de certeza de uma certa preposição ser verdadeira em $\varphi$, ou seja, um valor da função de favorabilidade que quantifica, à partida, a maior ou menor propensão para a ocorrência do fenómeno, de acordo com cada um dos factores considerados. Um valor de $f_{i}$ próximo de $\alpha$ significa que a garantia da preposição ser verdadeira é baixa, enquanto um valor de $f_{i}$ próximo de $\beta$ significa que a evidência $v(\varphi)$ suporta fortemente a preposição como sendo verdadeira.

Após a transformação, os valores de favorabilidade para cada tema cartográfico obtido são combinados através de uma regra de integração específica. 


\section{A interpretação bayesiana da função de favorabilidade}

A avaliação da susceptibilidade à ocorrência de deslizamentos utiliza um método indirecto assente numa abordagem estatística, em que a influência de cada factor condicionante é determinada com base nas relações espaciais observadas com a distribuição dos deslizamentos já ocorridos. Deste modo, a avaliação da susceptibilidade é efectuada de forma objectiva, visto que os factores condicionantes da instabilidade e suas inter-relações são quantificados estatisticamente com base na relação entre as áreas das classes de entidades.

A abordagem estatística pode ser aplicada segundo diferentes técnicas, que diferem essencialmente nos procedimentos estatísticos utilizados (análise univariada ou multivariada) e no tipo de unidades de terreno seleccionadas. No modelo aqui apresentado, o método de integração espacial utilizado baseia-se no teorema ou regra de Bayes. Este assenta sobretudo na análise condicionada, em que se tentam estabelecer as relações probabilísticas entre os factores condicionantes relevantes e a ocorrência de deslizamentos.

Considere-se um evento $\varepsilon$ correspondente à ocorrência de uma unidade de área de deslizamento e $T_{i j}$ a ocorrência de uma classe $j$ de um qualquer tema cartográfico $T_{i}$ utilizado como variável explicativa. A função de favorabilidade anterior pode ser interpretada como a probabilidade condicionada, traduzida por

$$
p_{i}=\left(P_{\varphi} \text { éverdadeiro } \mid T_{i j} \text { em } \varphi\right)
$$

em que $\varphi$ contenha pelo menos um dos «alvos» $\varepsilon$, dado o acontecimento $v_{i}$ em $\varphi$ para cada $T_{i}$,

$$
f_{i}(\varphi)=p_{i}\left(\mathcal{E} \text { éverdadeiro } \mid T_{i j} \text { em } \varphi\right)
$$

ou, outra interpretação possível pode ser

$$
f_{i}(\varphi)=p_{i}\left(T_{i j} \text { em } \varphi \mid \mathcal{E} \text { é verdadeiro }\right)
$$

onde $p(\varepsilon)$ é a probabilidade a priori de $\varphi$ conter um evento $\varepsilon, p_{i}\left(T_{i j}\right)$ é a probabilidade a priori que $\varphi$ tenha o evento $j$ no tema $T_{i}$, e $p_{i}\left(\varepsilon \mid T_{i j}\right)$ é a probabilidade de $\varepsilon$ ocorrer dado $T_{i j}$ já ter ocorrido. Ambas as probabilidades, a priori e condicionada, podem ser estimadas a partir do conjunto de dados, e o seu cálculo representa o primeiro passo da integração de dados cartográficos. A partir do momento em que se conhece a probabilidade de um acontecimento independente (ou seja, cada uma das classes $j$ do tema cartográfico $T_{i}$ ) ocorrer na área de estudo (espaço amostral $\Phi$ ), é possível obter a probabilidade de qualquer outro acontecimento (uma unidade de área de deslizamento $\varepsilon$ ) ocorrer condicionado por cada uma dessas classes.

Assim, como $\varepsilon$ e $T_{i}$ não são eventos independentes, pois os deslizamentos não podem ser considerados independentes dos factores que os condicionam, a 
probabilidade conjunta de ocorrência de $\varepsilon$ e $T_{i j}$ pode ser apresentada da seguinte forma:

$$
p\left(\mathcal{E} \cap T_{i j}\right)=p\left(\mathcal{E} \mid T_{i j}\right) p\left(T_{i j}\right) \quad(\mathrm{cf} .[2])
$$

em que $j$ corresponde a cada uma das classes ou categorias do tema $T_{i}$. Ou seja, a probabilidade conjunta de $\varepsilon$ e da classe $j$ de $T_{i}$ ocorrerem é igual à probabilidade da ocorrência de $T_{i j}$ vezes a probabilidade da ocorrência de $\varepsilon$ no caso de $T_{i j}$ ter ocorrido. Do mesmo modo, também é verdade que

$$
p\left(\mathcal{E} \cap T_{i j}\right)=p\left(T_{i j} \mid \mathcal{E}\right) p(\mathcal{E}), \quad(\text { cf. [3] })
$$

pelo que as equações [4] e [5] podem ser combinadas em

$$
p\left(\mathcal{E} T_{i j}\right) p\left(T_{i j}\right)=p\left(T_{i j} \mid \mathcal{E}\right) p(\mathcal{E}),
$$

pelo que:

$$
p(\mathcal{E})=\frac{p\left(\mathcal{E} \mid T_{i j}\right) p\left(T_{i j}\right)}{p\left(T_{i j} \mid \mathcal{E}\right)}=\frac{p\left(\mathcal{E} \cap T_{i j}\right)}{p\left(T_{i j} \mid \mathcal{E}\right)}=\frac{\frac{\text { Área }\left(\varepsilon \cap T_{i j}\right)}{\text { Área }(\Phi)}}{\frac{\text { Área }\left(\varepsilon \cap T_{i j}\right)}{\text { Área }(\varepsilon)}}=\frac{\text { Área }(\varepsilon)}{\text { Área }(\Phi)}
$$

é a probabilidade a priori de encontrar uma unidade de deslizamento $\varepsilon$;

$$
p\left(T_{i j}\right)=\frac{p\left(T_{i j} \mid \mathcal{E}\right) p(\mathcal{E})}{p\left(\mathcal{E} \mid T_{i j}\right)}=\frac{\frac{p\left(\mathcal{E} \cap T_{i j}\right)}{p(\mathcal{E})} p(\mathcal{E})}{\frac{p\left(\mathcal{E} \cap T_{i j}\right)}{p\left(T_{i j}\right)}}=\frac{\frac{\text { Área }\left(\varepsilon \cap T_{i j}\right)}{\text { Área }(\Phi)}}{\frac{\text { Área }\left(\varepsilon \cap T_{i j}\right)}{\text { Área }\left(T_{i j}\right)}}=\frac{\text { Área }\left(T_{i j}\right)}{\text { Área }(\Phi)}
$$

é a probabilidade a priori de encontrar uma classe $j$ em cada tema cartográfico $i$;

$$
p\left(\varepsilon \mid T_{i j}\right)=\frac{p\left(T_{i j} \mid \varepsilon\right) p(\varepsilon)}{p\left(T_{i j}\right)}=\frac{p\left(\varepsilon \cap T_{i j}\right)}{p\left(T_{i j}\right)}=\frac{\frac{\text { Área }\left(\varepsilon \cap T_{i j}\right)}{\text { Área }(\Phi)}}{\frac{\text { Área }\left(T_{i j}\right)}{\text { Área }(\Phi)}}=\frac{\text { Área }\left(\varepsilon \cap T_{i j}\right)}{\text { Área }\left(T_{i j}\right)}
$$

é a probabilidade condicionada, pois expressa a probabilidade de $\varepsilon$ ocorrer na condição de $T_{i j}$ já ter ocorrido, ou seja, $T_{i j}$ passa a ser o novo espaço amostral no qual ocorre $\varepsilon$, que vem substituir o espaço inicial. A probabilidade de encontrar um deslizamento $\varepsilon$ condicionado pela presença de $T_{i j}$ (classe $j$ da variável independente $T_{i}$ ) é, assim, igual ao quociente entre a probabilidade de ambos ocorrerem $\left(\varepsilon \cap T_{i j}\right)$ e a probabilidade do acontecimento dado. 
Devem ainda ser verificadas as seguintes condições:

$$
p\left(T_{11}\right)+p\left(T_{12}\right)+\ldots+p\left(T_{1 n}\right)=\sum_{j=1}^{n} p\left(T_{1 j}\right)=1
$$

visto que a união de todos os acontecimentos é o próprio espaço dos resultados $(\Phi)$, ou seja, a soma das áreas de cada classe de cada tema deve corresponder ao total do espaço amostral e a probabilidade de cada classe $j$ deve ser superior a zero $\left(p\left(T_{i j}\right)>0\right.$, para $\left.j=1,2, \ldots, n\right)$; se $T_{i 1}, T_{i 2}, \ldots, T_{i n}$ são acontecimentos mutuamente exclusivos e definem uma partição sobre o espaço total $\Phi$, cuja união corresponde à totalidade do espaço amostral, então para qualquer acontecimento $\varepsilon$ definido em $\Phi$ tem-se que (teorema da probabilidade total)

$$
\begin{aligned}
& p(\mathcal{E})=p\left(\mathcal{E} \cap T_{i 1}\right)+p\left(\mathcal{E} \cap T_{i 2}\right)+\ldots+p\left(\mathcal{E} \cap T_{i n}\right)= \\
& p\left(\mathcal{E} \mid T_{i 1}\right) p\left(T_{i 1}\right)+p\left(\mathcal{E} \mid T_{i 2}\right) p\left(T_{i 2}\right)+\ldots+p\left(\mathcal{E} \mid T_{i n}\right) p\left(T_{i n}\right)=\sum_{j=1}^{n} p\left(\mathcal{E} \mid T_{i j}\right) p\left(T_{i j}\right)
\end{aligned}
$$

em que $T_{i}$ resulta em um dos eventos mutuamente exclusivos $j=1, j=2, \ldots, j=n$; igualmente, para quaisquer três eventos $T_{1}, T_{2}$ e $T_{3}, T_{1}, T_{2}$ e $T_{3}, p\left(T_{1} \cap T_{2} \cap T_{3}\right)=$ $=p\left(T_{1}\right) p\left(T_{2} \mid T_{1}\right) p\left(T_{3} \mid T_{2} \cap T_{1}\right)$, pelo que se pode demonstrar que

$$
p\left(T_{1} \cap T_{2} \cap T_{3}\right)=p\left(T_{1}\right) \frac{p\left(T_{2} \cap T_{1}\right)}{P\left(T_{1}\right)} \cdot \frac{p\left(T_{3} \cap T_{2} \cap T_{1}\right)}{p\left(T_{2} \cap T_{1}\right)}=\frac{\text { Área }\left(T_{3} \cap T_{2} \cap T_{1}\right)}{\text { Área total }}
$$

ou seja, a probabilidade de ocorrência conjunta de $T_{1}, T_{2}$ e $T_{3}$ é igual à probabilidade de ocorrência de $T_{1}$ vezes a probabilidade de ocorrência de $T_{2}$, sabendo-se que $T_{1}$ ocorreu, vezes a probabilidade de ocorrência de $T_{3}$, sabendo-se que $T_{1}$ e $T_{2}$ ocorreram; para $n$ eventos, pode-se generalizar a seguinte expressão:

$$
\begin{aligned}
& p\left(T_{1} \cap T_{2} \cap \ldots \cap T_{n}\right)=p\left(T_{1}\right) p\left(T_{2} \mid T_{1}\right) \ldots p\left[T_{n-1} \mid\left(T_{1} \cap T_{2} \cap \ldots \cap T_{n-2}\right)\right] p\left[T_{n} \mid\left(T_{1} \cap T_{2} \cap \ldots \cap T_{n-1}\right)\right] \\
& =\frac{\text { Área }\left(T_{1} \cap T_{2} \cap \ldots \cap T_{n}\right)}{\text { Área total }}
\end{aligned}
$$

Deste modo, se $T_{1 j}, T_{2 j}, \ldots, T_{n j}$ definem uma partição sobre a totalidade da área de estudo, então, para $\varepsilon$ definido nesse espaço amostral, $\operatorname{com} p(\varepsilon)>0$ :

$$
p\left(\mathcal{E} \mid T_{i j}\right)=\frac{p\left(T_{i j} \cap \mathcal{E}\right)}{p\left(T_{i j}\right)}=\frac{p\left(T_{i j}\right) p\left(\mathcal{E} \mid T_{i j}\right)}{\sum_{j=l}^{n} p(\mathcal{E}) p\left(T_{i j} \mid \mathcal{E}\right)} \quad \text { (cf.[9]) }
$$

em que o numerador define a probabilidade de intersecção de dois acontecimentos e o denominador obedece ao teorema da probabilidade total, anteriormente definido pela expressão [11]. 
Pode, assim, calcular-se a probabilidade de ocorrência de $\varepsilon$, dada a ocorrência conjunta de dois acontecimentos $j$, provenientes de dois temas distintos $T_{1}$ e $T_{2}$ (Chung e FabBri, 1993):

$$
p\left(\mathcal{E} \mid T_{1 j} \cap T_{2 j}\right)=\frac{p\left(\mathcal{E} \mid T_{1 j}\right) p\left(\mathcal{E} \mid T_{2 j}\right)}{p(\mathcal{E})} \cdot \frac{p\left(T_{1 j}\right) p\left(T_{2 j}\right)}{p\left(T_{1 j} \cap T_{2 j}\right)}
$$

A predição da susceptibilidade à ocorrência de deslizamentos é, consequentemente, considerada a probabilidade condicionada conjunta duma dada pequena área ser afectada por um futuro deslizamento, condicionado pelas respectivas características do terreno. Para $n$ classes deve ser usada a seguinte fórmula geral

$$
p\left(\mathcal{E} \mid T_{1 j} \cap T_{2 j} \cap \ldots \cap T_{n j}\right)=\frac{\prod_{i=1}^{n} p\left(\mathcal{E} \mid T_{i j}\right) p\left(T_{i j}\right)}{\left(\prod_{l}^{n-1} p(\mathcal{E})\right) p\left(T_{1 j} \cap T_{2 j} \cap \ldots \cap T_{n j}\right)},
$$

onde $p(\varepsilon), p\left(T_{i j}\right)$ e $p\left(\varepsilon \mid T_{i j}\right)$ podem ser calculados, respectivamente, através das expressões [7], [8] e [9], e $p\left(T_{1 j} \cap T_{2 j} \cap \ldots \cap T_{n j}\right)$ é a probalidade de encontrar cada uma das intersecções de todos os temas na área, ou seja, de $T_{1 j}$ cruzar com $T_{2 j}, \ldots, T_{n j}$, e assim sucessivamente, definida pela expressão [13].

Como se constata, de acordo com o teorema de Bayes, os valores de probabilidade tornam-se cada vez menores à medida que se aumenta o número de variáveis independentes utilizadas no modelo. A expressão $\prod_{1}^{n-1} p(\varepsilon)$ no denominador permite, assim, que a soma de todos os valores de probabilidade da área de estudo seja igual a 1, impedindo ainda que os valores de probabilidade assumam dimensões demasiado reduzidas à medida que aumenta o número de variáveis independentes. No caso presente, obtém-se a probabilidade de encontrar um deslizamento $(\varepsilon)$ tendo como base as cinco variáveis independentes anteriormente referidas, através da expressão seguinte:

$$
\begin{aligned}
& p(\mathcal{E} \mid \text { Dec } \cap \text { Dep } \cap \text { Lit } \cap U \text { sol } \cap \text { Exp })= \\
& =\frac{p(\mathcal{E} \mid \operatorname{Dec}) p(\operatorname{Dec}) p(\mathcal{E} \mid \text { Dep }) p(\text { Dep }) \cdot p(\mathcal{E} \mid L i t) p(\text { Lit }) p(\mathcal{E} \mid U \operatorname{sol}) p(\text { Usol }) p(\mathcal{E} \mid \operatorname{Exp}) p(\operatorname{Exp})}{[p(\mathcal{E})]^{4} \cdot p(\text { Dec } \cap \text { Dep } \cap \text { Lit } \cap U \operatorname{sol} \cap \operatorname{Exp})}
\end{aligned}
$$

onde Dec corresponde ao declive, Dep aos depósitos superficiais, Lit à litologia, Usol ao uso do solo, e Exp à exposição das vertentes.

$\mathrm{O}$ resultado final varia entre $0 \mathrm{e} 1$, correspondendo os valores altos às probabilidades mais elevadas e os valores baixos às probabilidades mais baixas de ocorrência de deslizamento. Como é óbvio, a multiplicação das probabilidades condicionadas implica que a probabilidade final de encontrar um deslizamento 
num local será nula desde que o valor zero esteja associado a qualquer classe de uma variável aí presente. Isto sucede pois um factor pode actuar como inibidor do fenómeno (por exemplo, declive nulo), ainda que os outros factores apresentem características que, em princípio, facilitariam a sua ocorrência.

\section{PROCEDIMENTOS PARA A AVALIAÇÃO DA SUSCEPTIBILIDADE}

De acordo com o referido anteriormente, a avaliação da susceptibilidade à ocorrência de deslizamentos segue os passos seguintes (fig. 5):

- a selecção do mapa de eventos e dos mapas que representam os factores condicionantes;

- a obtenção das probabilidades a priori de encontrar uma unidade de área de deslizamento na área de estudo e de encontrar cada uma das classes de cada tema cartográfico, e cálculo dos respectivos valores da função de favorabilidade (probabilidade condicionada);

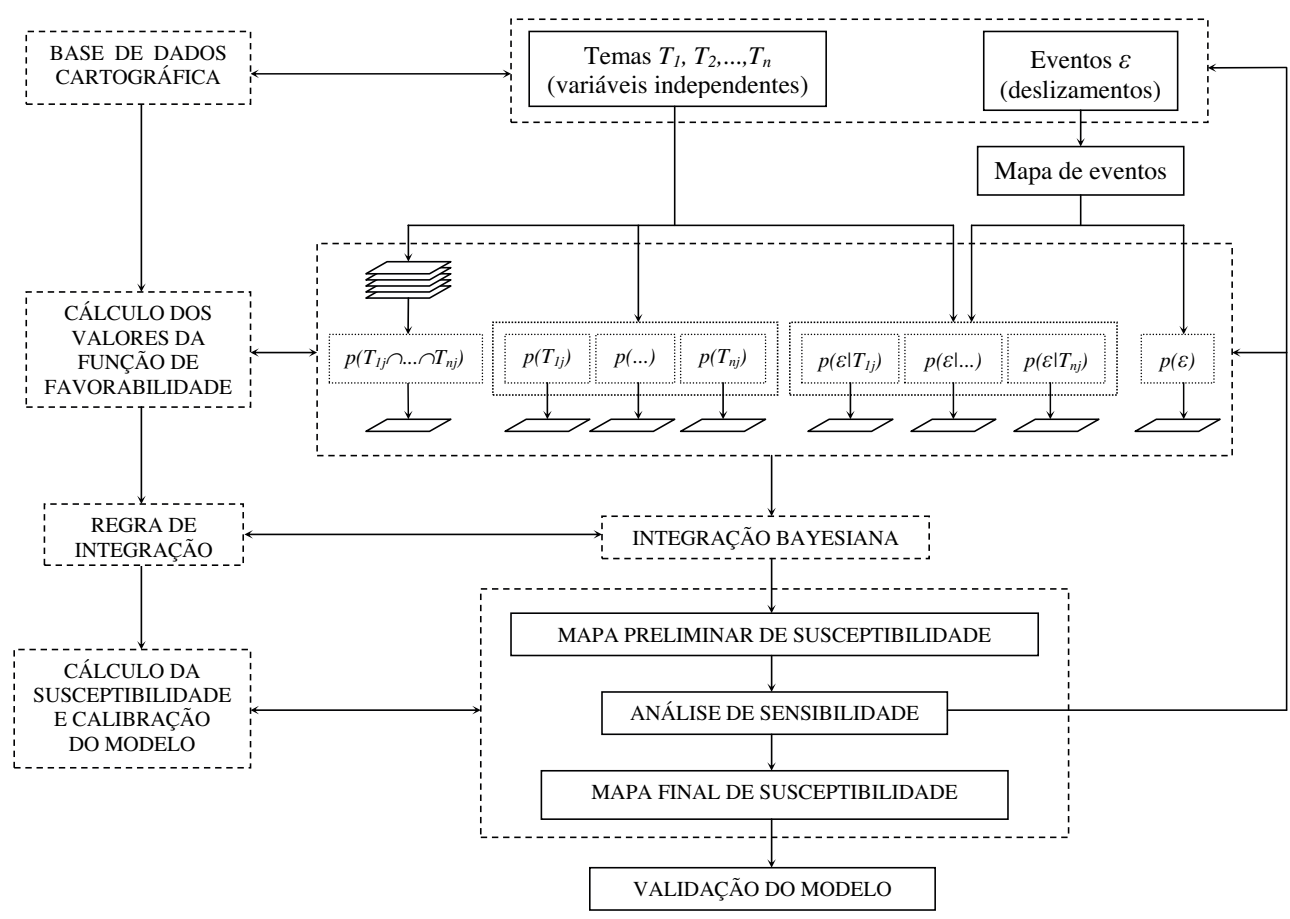

Fig. 5 - Sequência de procedimentos para a integração de informação geográfica com vista ao cálculo da susceptibilidade à ocorrência de deslizamentos. Fig. 5 - The main process steps in favourability function calculation to bayesian data integration for landslide susceptibility prediction. 
- a integração dos dados espaciais anteriores com base na regra de Bayes;

- a análise de sensibilidade do modelo, com vista ao melhoramento dos resultados obtidos, que consiste na selecção e utilização de diferentes combinações de variáveis, e modificação dos valores da função de favorabilidade de acordo com o conhecimento pericial; foi com base na análise de sensibilidade que foram retiradas do modelo as variáveis das distâncias às estradas e aos cursos de água;

- a validação do modelo, verificando em que medida os resultados obtidos permitem prever a ocorrência de novos eventos.

A análise de sensibilidade e a validação do modelo exigem a intersecção prévia dos deslizamentos com cada mapa preliminar de susceptibilidade. Para tal, estes mapas são classificados, seleccionando-se a área com valor igual ou acima de um determinado limite de probabilidade (valor 1), em oposição à restante área com valor inferior a esse limite (valor 0). A quantificação do grau de sucesso ou de predição é obtida sobrepondo cada um destes mapas de probabilidade obtido a partir do conjunto de deslizamentos de treino com os deslizamentos usados para a validação do modelo. Os melhores resultados são obtidos quando, para um determinado conjunto de resultados, uma área mais pequena com probabilidades elevadas integra a generalidade dos deslizamentos usados para a validação do modelo.

\section{Os mapas de eventos}

O modelo de avaliação da susceptibilidade exige a presença de um tema cartográfico em que estejam representados os eventos que se pretendem prever. Os mapas de eventos constituem, assim, condição essencial, não apenas para o funcionamento do modelo, mas também para avaliar a sua capacidade para prever a ocorrência dos deslizamentos. Um mapa de eventos é obtido a partir do ficheiro de distribuição de um tipo particular de movimentos de vertente, neste caso a totalidade dos deslizamentos translacionais superficiais (fig. 4A), e constitui um ficheiro binário em que o valor 1 corresponde à sua presença e o valor 0 à sua ausência.

No caso da avaliação da taxa de predição, ou seja, a determinação da capacidade do modelo para prever a ocorrência de novos deslizamentos, é necessário dividir o conjunto dos deslizamentos em duas amostras: uma das amostras é usada como ficheiro de modelação e a outra para verificar a validade dos resultados no modelo de predição. Neste trabalho, o conjunto dos deslizamentos translacionais superficiais foi separado em duas amostras através de um processo aleatório (fig. 6), que seguiu três passos:

a) a geração de uma série aleatória, de 1 a $n$, para o número total de deslizamentos; 
b) a contagem, divisão e selecção de metade dos deslizamentos, efectuada com base na mediana $(n / 2)$, sendo $n$ o número total de deslizamentos utilizados no estudo;

c) o cálculo de densidade para cada mapa de eventos com cerca de 50\% dos deslizamentos.

A informação acerca da densidade dos deslizamentos tem como principal finalidade verificar a representatividade de cada amostra em relação com as diferentes classes para cada tema cartográfico independente. Assim, os valores de densidade para as amostras de 50\% dos deslizamentos devem ser similares, e corresponder aproximadamente a metade dos valores encontrados para o total do conjunto dos deslizamentos. Os três passos anteriores foram repetidos até que esta condição se verificasse.

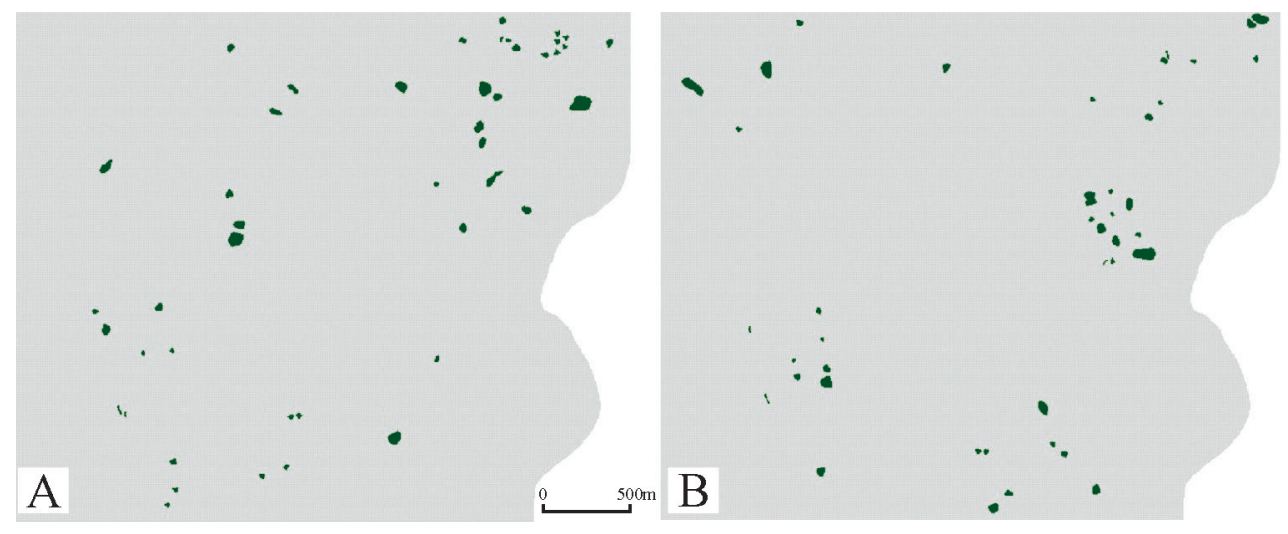

Fig. 6 - Distribuição espacial dos conjuntos de deslizamentos gerados aleatoriamente: A) amostra utilizada para integração no modelo e B) amostra utilizada para avaliação da capacidade de predição do modelo.

Fig. 6 - Spatial distribution of random landslide groups: A) sample used for model integration and B) sample used to evaluate the prediction power of the model.

\section{A probabilidade a priori e a probabilidade condicionada}

Como foi demonstrado, as probabilidades a priori $\left(p_{p}\right)$ e condicionada $\left(p_{c}\right)$ podem ser obtidas pelas equações [7], [8] e [9]. As duas primeiras expressões representam, respectivamente, a frequência relativa dos deslizamentos e de cada classe na área de estudo $-p\left(T_{i j}\right)$; a última, a probabilidade de encontrar uma unidade de área (célula) deslizada em cada uma das classes anteriores $-p\left(\varepsilon \mid T_{i j}\right)$, ou seja, os valores da função de favorabilidade.

Os declives entre 5 e $15^{\circ}$ ocupam quase $60 \%$ da área de estudo; os declives acima de $20^{\circ}$ ocupam pouco mais de $16 \%$, e correspondem em geral às vertentes dos vales encaixados da ribeira de Fanhões e, essencialmente, do rio Trancão (fig. 4B). Verifica-se claramente que a probabilidade de encontrar uma unidade 
de área correspondente a um deslizamento aumenta de forma acentuada com o aumento do declive $\left(r^{2}=0,96\right)$; a probabilidade é bastante reduzida na classe de declive mais fraco $\left(\mathrm{p}_{\mathrm{c}}=0,00075\right)$, verificando-se um aumento bastante acentuado até aos $20^{\circ}$, valor a partir do qual o crescimento se processa de forma mais lenta, até atingir $\mathrm{p}_{\mathrm{c}}=0,04337$ na classe superior a $40^{\circ}$ (fig. 7).

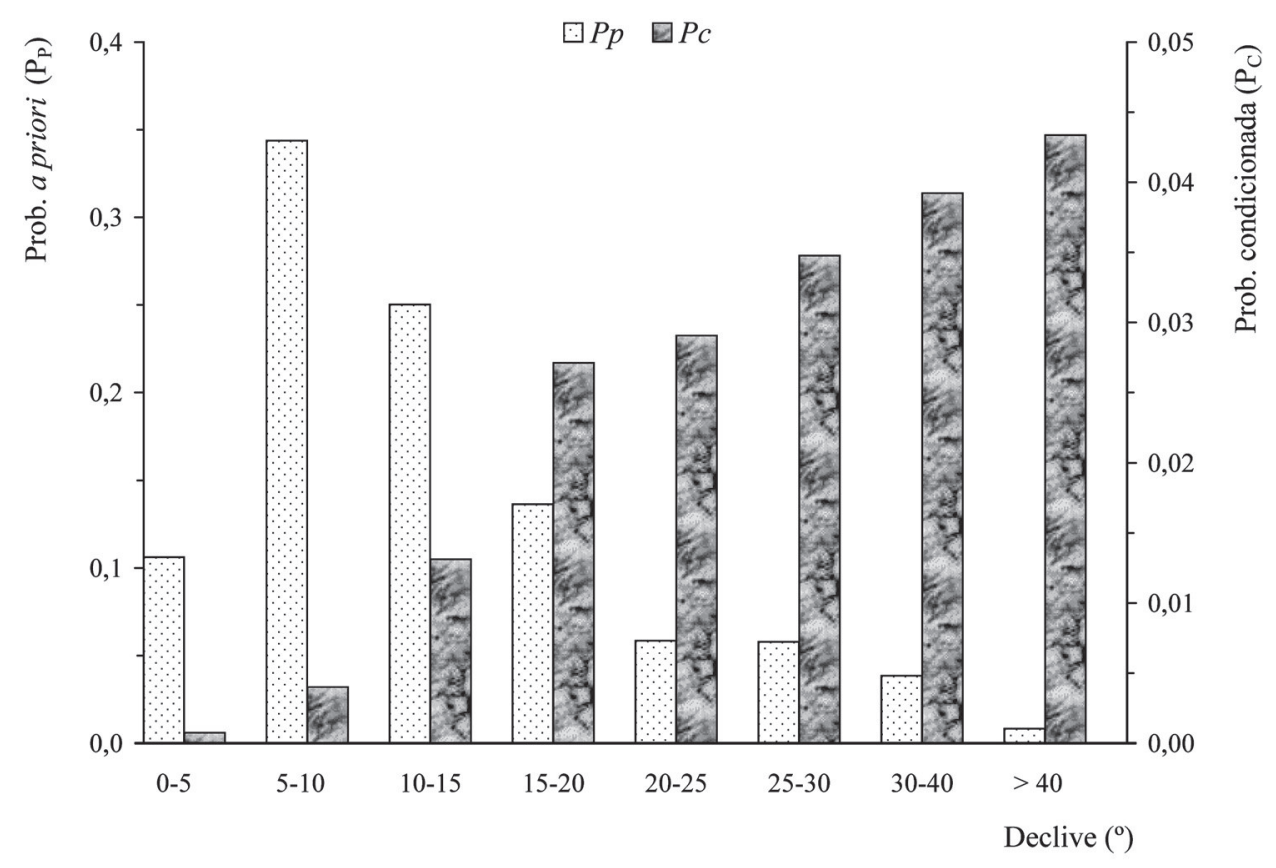

Fig. 7 - Probabilidades a priori $\left(\mathrm{P}_{\mathrm{P}}\right)$ e condicionada $\left(\mathrm{P}_{\mathrm{C}}\right)$ para as classes de declive. Fig. $7-$ Prior $\left(P_{P}\right)$ and conditional $\left(P_{C}\right)$ probabilities for slope classes.

As áreas planas ocupam uma área muito reduzida (cerca de 0,9\%, ou seja, $\left.\mathrm{p}_{\mathrm{p}}=0,009\right)$ e correspondem às planícies aluviais, especialmente no vale do Trancão perto de Bucelas, e a algumas superfícies terraplanadas (fig. 4C). O histograma das exposições (fig. 8) configura claramente a morfologia do reverso da costeira, sendo evidente a predominância de áreas com inclinação para Sul $\left(24,4 \%\right.$, ou $\left.\mathrm{p}_{\mathrm{p}}=0,24\right)$ e Sudeste $\left(17,3 \%\right.$, ou $\left.\mathrm{p}_{\mathrm{p}}=0,17\right)$. As vertentes expostas a Noroeste, ou seja, com exposição contrária à inclinação geral das camadas geológicas, são as que apresentam maior probabilidade de possuir deslizamentos translacionais superficiais $\left(p_{c}=0,02973\right)$. As vertentes com exposições a Oeste, Nordeste e Este possuem também probabilidades condicionadas elevadas. Pelo contrário, as vertentes expostas a Norte, Sudeste e Sul possuem probabilidades relativamente reduzidas, inferiores a 0,015. Nas áreas planas nunca se verificaram deslizamentos $\left(\mathrm{p}_{\mathrm{c}}=0\right)$. 


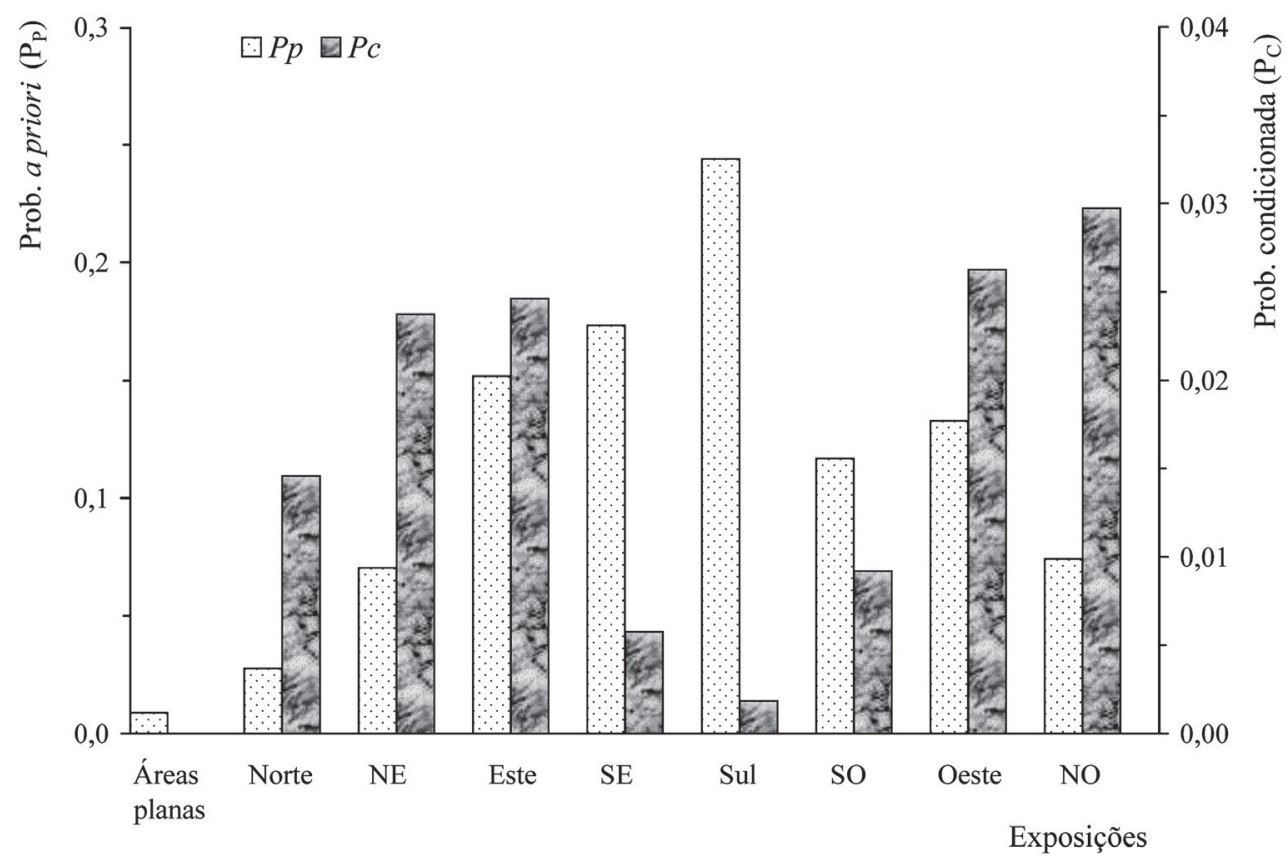

Fig. 8 - Probabilidades a priori $\left(\mathrm{P}_{\mathrm{P}}\right)$ e condicionada $\left(\mathrm{P}_{\mathrm{C}}\right)$ para as classes de exposição.

Fig. 8 - Prior $\left(P_{P}\right)$ and conditional $\left(P_{C}\right)$ probabilities for slope aspect classes.

No caso da litologia (fig. 4D), embora os basaltos e tufos vulcânicos constituam a unidade litológica mais extensa na área de estudo $\left(59 \%\right.$, ou $\left.\mathrm{p}_{\mathrm{p}}=0,59\right)$, é aquela que regista a menor probabilidade de ocorrência de deslizamentos $\left(p_{c}=0,00712\right)$. Pelo contrário, a probabilidade é substancialmente elevada nas áreas de arenitos com intercalações calcárias $\left(\mathrm{p}_{\mathrm{c}}=0,06929\right)$, embora ocupem apenas $1,5 \%\left(\mathrm{p}_{\mathrm{p}}=0,015\right)$ da área (fig. 9). Outros afloramentos significativos são os calcários e margas $\left(\mathrm{p}_{\mathrm{p}}=0,28\right)$ e os calcários com rudistas $\left(\mathrm{p}_{\mathrm{p}}=0,12\right)$, respectivamente com $p_{c}=0,02431$ e $p_{c}=0,01728$.

As áreas cobertas com depósitos de vertente com espessura superior a $0,5 \mathrm{~m}$ ocupam $46,7 \%\left(\mathrm{p}_{\mathrm{p}}=0,47\right)$ da área de estudo (figs. $4 \mathrm{E}$ e 10$)$, e é aqui que ocorre a grande maioria dos deslizamentos translacionais superficiais $\left(\mathrm{p}_{\mathrm{c}}=0,02626\right)$. Os depósitos menos espessos aparecem em $51,8 \%\left(\mathrm{p}_{\mathrm{p}}=0,52\right)$ da área, e têm associada uma probabilidade de ocorrência de deslizamentos bastante mais baixa (fig. 10). Nas planícies aluviais e nos terraços fluviais nunca ocorrem deslizamentos $\left(\mathrm{p}_{\mathrm{c}}=0\right)$.

Em relação aos tipos de cobertura do solo, a maior parte da área $\left(\mathrm{p}_{\mathrm{p}}=0,53\right)$ é ocupada por vegetação herbácea (fig. 11); a área com vegetação arbustiva densa tem também uma presença importante $\left(\mathrm{p}_{\mathrm{p}}=0,20\right)$, e os restantes tipos são menos representativos. A maior probabilidade de encontrar deslizamentos trans- 


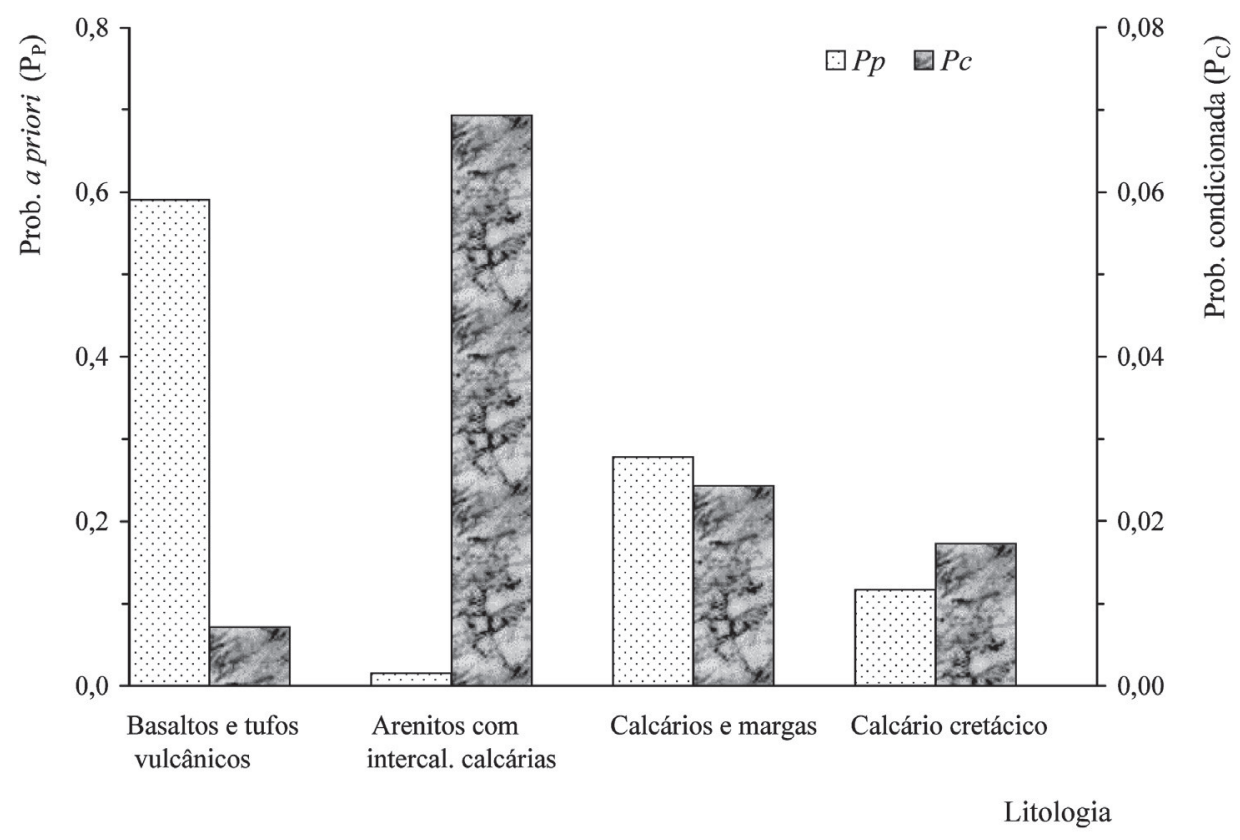

Fig. 9 - Probabilidades a priori $\left(\mathrm{P}_{\mathrm{P}}\right)$ e condicionada $\left(\mathrm{P}_{\mathrm{C}}\right)$ para cada tipo litológico. Fig. 9 - Prior $\left(P_{P}\right)$ and conditional $\left(P_{C}\right)$ probabilities for lithological units.

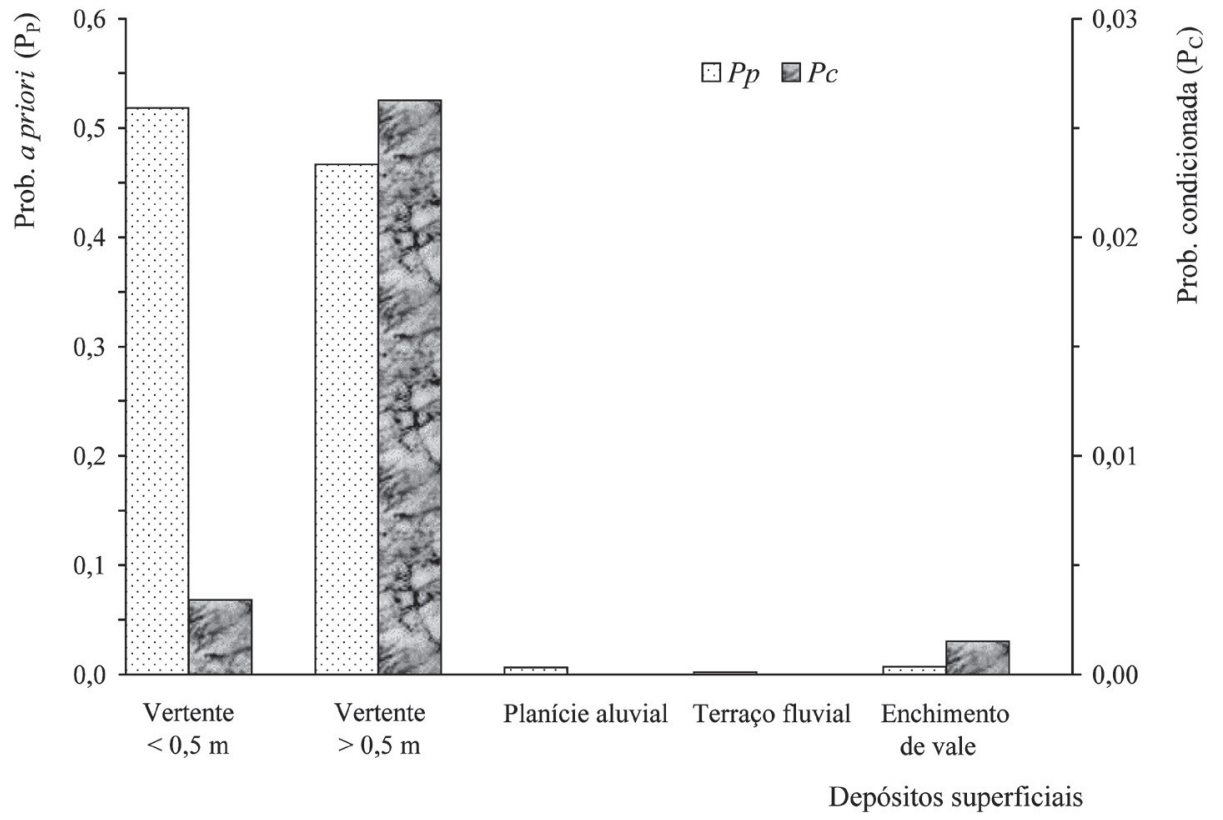

Fig. 10 - Probabilidades a priori $\left(\mathrm{P}_{\mathrm{P}}\right)$ e condicionada $\left(\mathrm{P}_{\mathrm{C}}\right)$ para os depósitos superficiais. Fig. 10 - Prior $\left(P_{P}\right)$ and conditional $\left(P_{C}\right)$ probabilities for superficial deposits. 


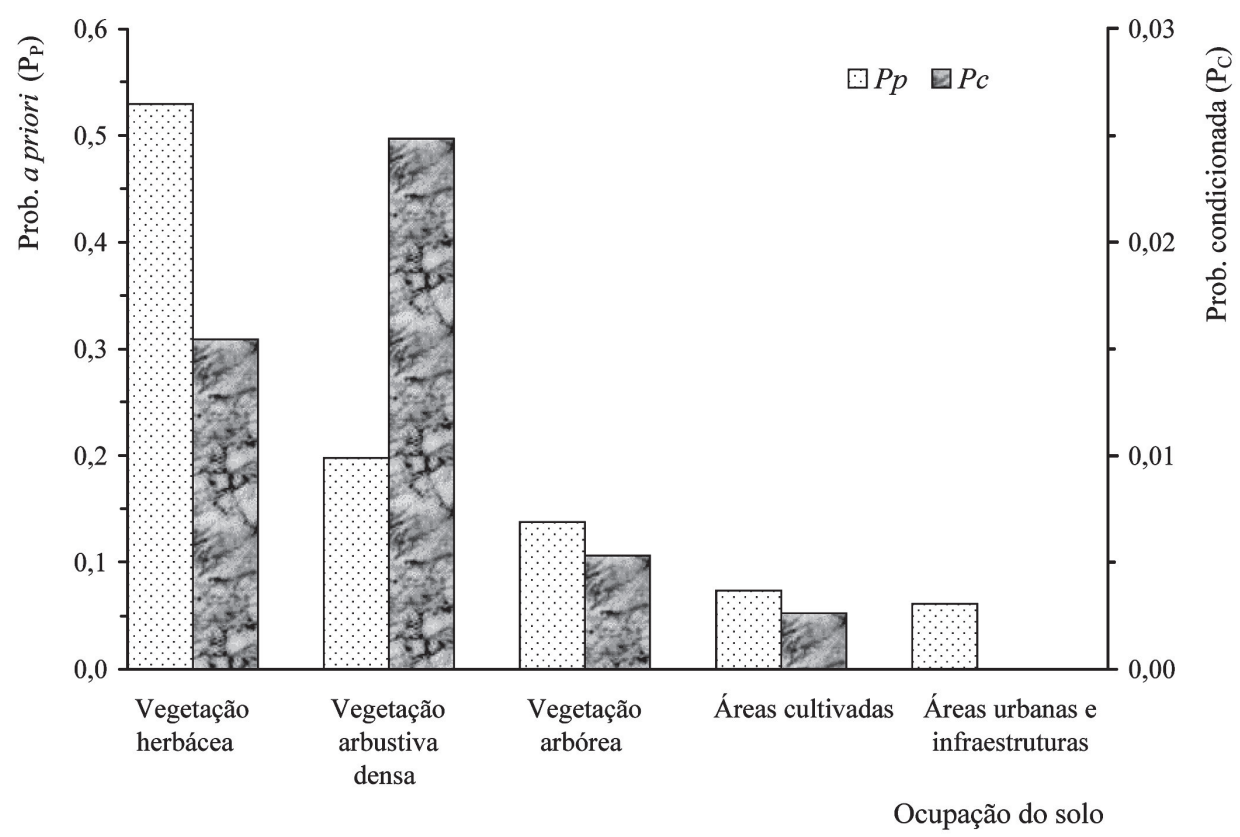

Fig. 11 - Probabilidades a priori $\left(\mathrm{P}_{\mathrm{P}}\right)$ e condicionada $\left(\mathrm{P}_{\mathrm{C}}\right)$ para as classes de uso do solo. Fig. $11-\operatorname{Prior}\left(P_{P}\right)$ and conditional $\left(P_{C}\right)$ probabilities for land use and vegetation cover classes.

lacionais superficiais ocorre em áreas ocupadas por vegetação arbustiva densa $\left(p_{c}=0,02484\right)$, a que se seguem as áreas com vegetação herbácea $\left(p_{c}=0,01546\right)$. Nas áreas com vegetação arbórea e nas áreas cultivadas, as probabilidades reduzem-se substancialmente, com $p_{c}=0,00532$ e $p_{c}=0,00262$, respectivamente. Nas áreas urbanas e ocupadas por infra-estruturas não foram detectados deslizamentos translacionais superficiais $\left(\mathrm{p}_{\mathrm{c}}=0\right)$.

Conclui-se, assim, que a probabilidade de encontrar uma unidade de área afectada por um deslizamento translacional superficial será mais elevada quando se conjuguem as seguintes condições: declive elevado $\left(>40^{\circ}\right)$, vertentes expostas a Noroeste ou a Oeste, substrato constituído por arenitos com intercalações calcárias, coberto por depósitos superficiais com espessura superior a 0,5m, em áreas ocupadas por vegetação arbustiva densa ou vegetação herbácea. Pelo contrário, a probabilidade será nula $(\mathrm{p}=0)$ sempre que se verifique qualquer uma destas condições: áreas planas, planícies aluviais ou terraços fluviais, e áreas urbanas ou ocupadas por infraestruturas. Deverão ainda obter-se probabilidades baixas quando se conjuguem declives inferiores a $5^{\circ}$, vertentes expostas a Sudeste, substrato constituído por basaltos e tufos vulcânicos com cobertura de depósitos com espessura inferior a $0,5 \mathrm{~m}$, e áreas ocupadas por vegetação arbórea ou terrenos cultivados.

Alguns valores de probabilidade condicionada apenas encontram explicação na autocorrelação entre factores condicionantes. É o caso, por exemplo, 
do valor de probabilidade de ocorrência muito baixo em áreas ocupadas por terrenos de cultivo, visto que, à partida, seriam de esperar valores mais elevados em terrenos desprotegidos. No entanto, a presença de áreas de cultivo tem uma relação muito próxima com a distribuição espacial do declive, pelo que este factor se sobrepõe ao factor uso do solo. De facto, a maior parte da área cultivada $(52,3 \%)$ coincide com a classe de declive $5-10^{\circ}$, e quase $93 \%$ está situada em terrenos com declive igual ou inferior a $15^{\circ}$. Os terrenos com declive superior a $20^{\circ}$, embora ocupem $16,3 \%\left(\mathrm{p}_{\mathrm{p}}=0,16\right)$ da área de estudo e possuam as probabilidades de encontrar deslizamentos translacionais superficiais mais elevadas (sempre acima de $\mathrm{p}_{\mathrm{c}}=0,029$ ), contêm apenas $1,5 \%$ do total da área cultivada.

\section{Cálculo dos valores de susceptibilidade à ocorrência de deslizamentos}

Para obtenção dos valores de susceptibilidade à ocorrência de deslizamentos translacionais superficiais, as diversas probabilidades são calculadas através do cruzamento sucessivo dos vários temas cartográficos em SIG, até se gerarem as componentes para o cálculo da expressão [17]. Obtém-se, assim, uma hierarquização das células com valores entre 0 e 1 . O valor 0 indica a certeza de não ocorrência de deslizamentos nesse local, de acordo com os dados utilizados no modelo, devido ao facto de existir pelo menos um factor que actua no sentido de limitar o fenómeno. Pelo contrário, e como é natural, o valor 1 nunca é alcançado. Esse valor indicaria a certeza de ocorrência, implicando uma coincidência perfeita das classes de maior probabilidade condicionada de cada tema cartográfico, sendo ainda condição essencial que todas elas possuíssem probabilidade máxima, ou seja, valor 1. A figura 12 representa os valores classificados para o modelo de predição obtido pela aplicação da probabilidade bayesiana, tomando em conta a totalidade dos deslizamentos translacionais superficiais. Como seria de esperar, a integração bayesiana gera valores de probabilidade geralmente muito pequenos: $7 \%$ da área possui probabilidade nula $(\mathrm{p}=0), 98,4 \%$ possui valores de probabilidade inferiores ou iguais a 0,1 (fig. 13), e apenas $0,2 \%$ das células possuem valores acima de 0,2 . Este facto não indica necessariamente fracos valores de susceptibilidade, visto que, tal como foi referido, os valores não correspondem a uma probabilidade absoluta, mas sim a uma hierarquização da probabilidade de encontrar o fenómeno que se está a estudar.

Como pode ser observado na figura 13 , os deslizamentos translacionais superficiais não estão presentes em áreas com probabilidade nula, e a maior parte dos eventos ocorrem na classe de 0,01 a 0,1 (76,5\%). Na classe de maior probabilidade $(0,1-1)$ está presente apenas $5 \%$ da área dos deslizamentos; no entanto, isto deve-se apenas à reduzida área que esta classe ocupa na área de estudo: quando consideramos a área de cada classe ocupada por deslizamentos, esta classe sobressai com 4,5\%, logo seguida da classe $0,01-0,1$ com $4 \%$; as restantes classes de probabilidade possuem valores substancialmente mais reduzidos. A taxa de sucesso é cerca de $35 \%$, quando os $10 \%$ de células com maior susceptibilidade são considerados, e sobe para $63 \%$ e $83 \%$ quando a área susceptível se estende, respectivamente, a $20 \%$ e $30 \%$ do total da superfície (fig. 14). 


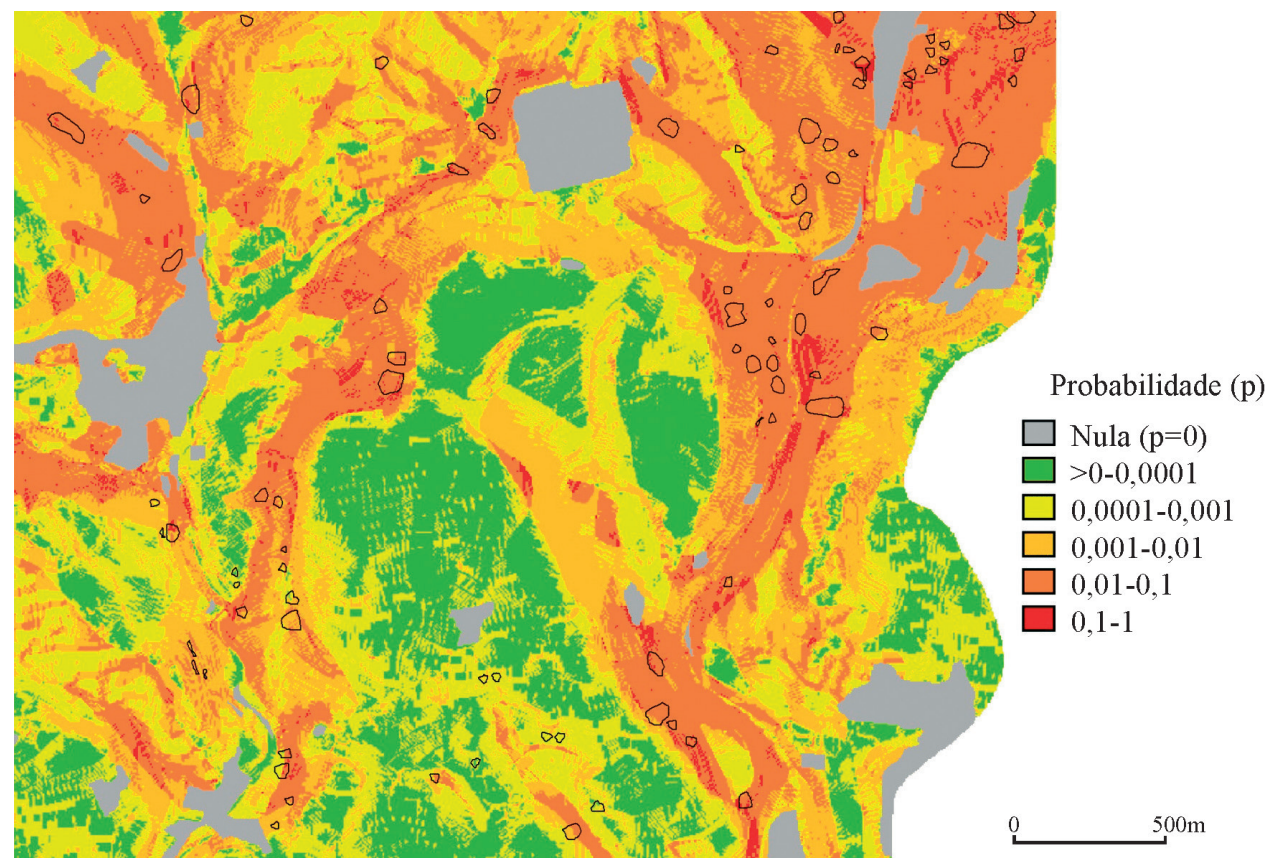

Fig. 12 - Probabilidade de ocorrência de deslizamentos translacionais superficiais na área de Fanhões-Trancão, baseada na integração do conjunto dos eventos (polígonos no mapa) no modelo de susceptibilidade.

Fig. 12 - Probability of occurence of shallow translational landslides in the Fanhões-Trancão test site, based on the complete event data set (polygons on map) integration in the susceptibility model.

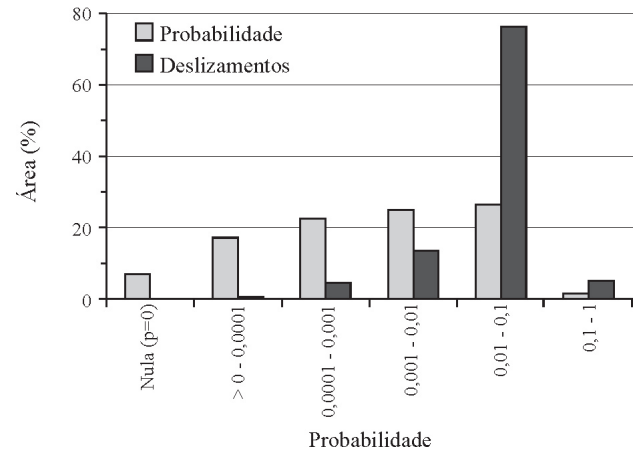

Fig. 13 - Frequência da probabilidade e fracção do total de deslizamentos em cada classe de probabilidade (de acordo com a fig. 12).

Fig. 13 - Frequency of probability classes and percentage of total landslide area in each probability class (according to figure 12).

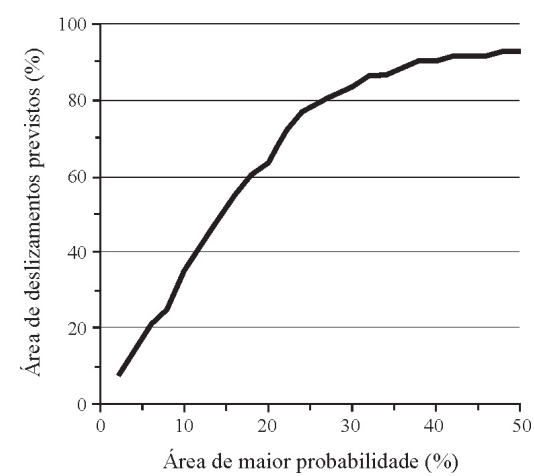

Fig. 14 - Área de deslizamentos previstos (taxa de sucesso) para os $50 \%$ de área com maior valor de probabilidade, baseada no total de eventos.

Fig. 14 - Success-rate curve of susceptibility assessment for the $50 \%$ area with higher values of probability, based on the complete landslide data set. 
As áreas previstas como as mais perigosas têm uma relação próxima com as vertentes mais declivosas, mesmo em condições litológicas e de ocupação do solo distintas, embora as áreas com cobertura arbórea sejam geralmente consideradas seguras. Esta predição confirma que a declive das vertentes é o principal factor condicionante dos deslizamentos translacionais superficiais, não apenas na área de amostra mas no conjunto da região a Norte de Lisboa (ZÊZERE, 1997).

As classes de menor susceptibilidade, não nula e inferior ou igual a 0,01, que ocupam a maior parte da superfície $(64,7 \%)$, integram $18,5 \%$ da área instabilizada. Trata-se, nestes casos, de deslizamentos translacionais superficiais essencialmente condicionados por factores que não puderam ser considerados nos modelos de predição, tais como a proximidade aos canais fluviais e aos taludes das estradas.

\section{A avaliação do desempenho do modelo}

A avaliação da susceptibilidade com base na totalidade dos eventos conhecidos deve ser seguida da validação da metodologia, em que se quantifica a capacidade do modelo para prever a ocorrência espacial novos deslizamentos. Os modelos de predição foram levados a efeito usando as duas amostras geradas aleatoriamente, e os resultados obtidos são bastante similares, pelo que apenas um dos casos é aqui referido e analisado (fig. 6).

A figura 15 representa os valores classificados para o modelo de predição tomando como dados de referência apenas 50\% dos deslizamentos translacionais superficiais (fig. 6A). Os resultados obtidos, quando confrontados com os eventos utilizados para a validação do modelo (fig. 6B), ficam ligeiramente aquém dos alcançados quando é utilizada a totalidade dos deslizamentos. Como se pode observar na figura 16, existe uma pequena área instabilizada coincidente com áreas de probabilidade nula $(0,3 \%)$, e a preponderância da fracção da área instabilizada na classe 0,01-0,1 não é tão evidente (cerca de 60\%), embora quase $89 \%$ da área dos deslizamentos utilizada para validar o modelo ocorra nas três classes de maior probabilidade. A taxa de predição é cerca de $33 \%$ quando os $10 \%$ de células com maior susceptibilidade são considerados, e sobe para $59 \%$ e $78 \%$ quando se consideram, respectivamente, $20 \%$ e $30 \%$ da área com maior susceptibilidade.

Nas áreas das classes de menor susceptibilidade, inferior ou igual a 0,01, que ocupam a maior parte da superfície $(79,5 \%)$, pode ser encontrada $19,8 \%$ da área deslizada.

\section{CONSIDERAÇÕES FINAIS}

O modelo baseado nas funções de probabilidade recorrendo à integração bayesiana dos dados espaciais permite a quantificação das unidades de terreno de acordo com a susceptibilidade à ocorrência de deslizamentos translacionais 


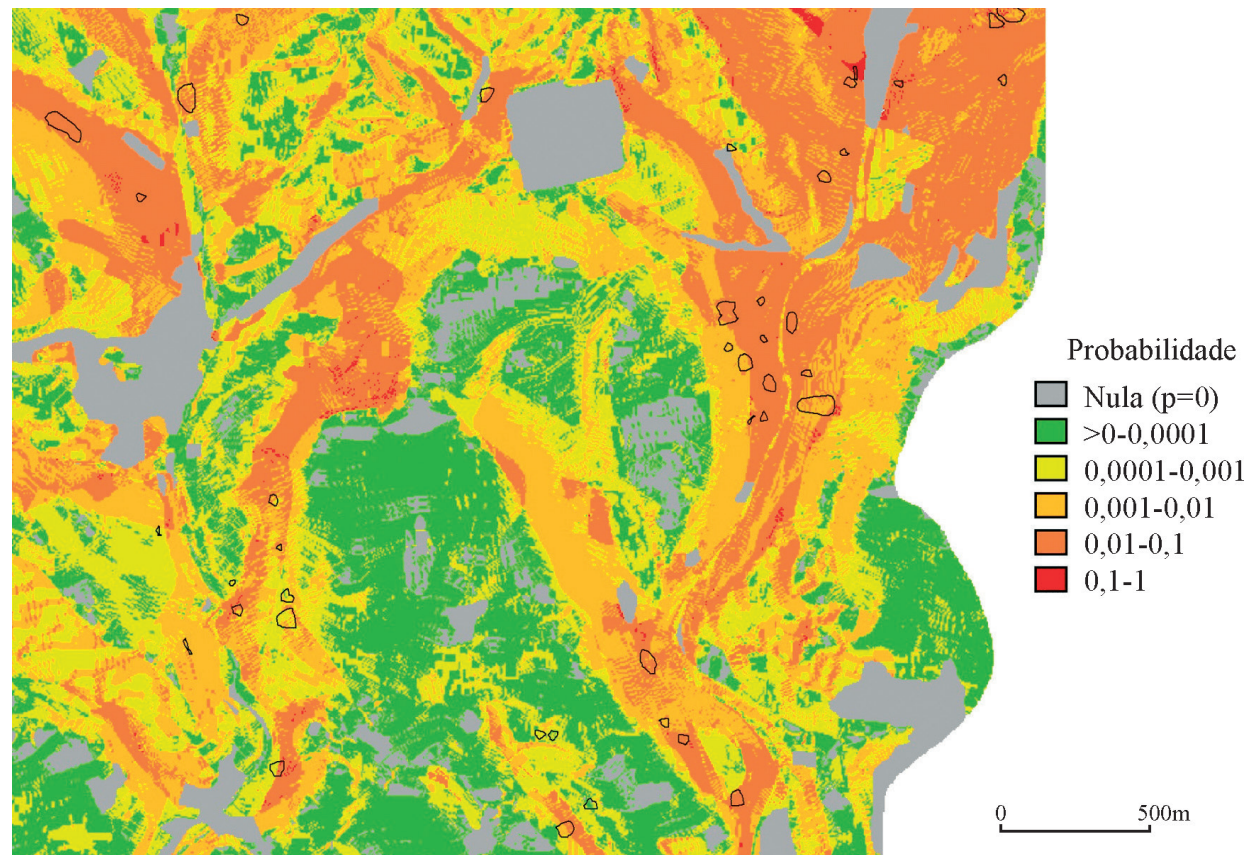

Fig. 15 - Probabilidade de ocorrência de deslizamentos translacionais superficiais na área de Fanhões-Trancão, baseada na integração de 50\% dos eventos no modelo de susceptibilidade (os polígonos no mapa representam os eventos utilizados para validação - fig. 6B).

Fig. 15 - Probability of occurence of shallow translational landslides in the FanhóesTrancão test site, based on integration of $50 \%$ of the event data set in the susceptibility model (polygons on map are events used for model validation - figure 6B).

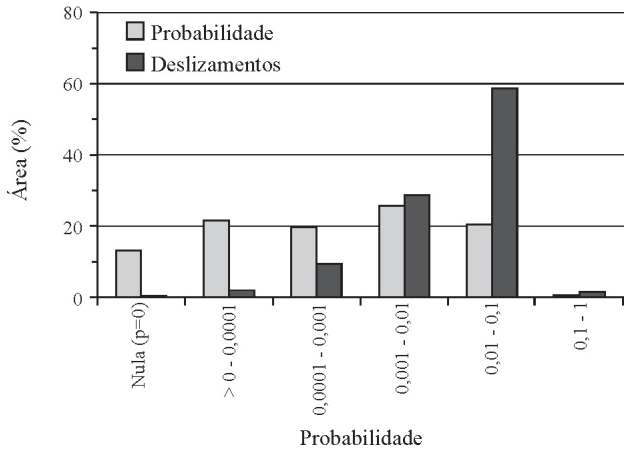

Fig. 16 - Frequência da probabilidade e fracção do total de deslizamentos em cada classe de probabilidade (de acordo com a fig. 15).

Fig. 16 - Frequency of probability classes and percentage of total landslide area in each probability class (according to figure 15).

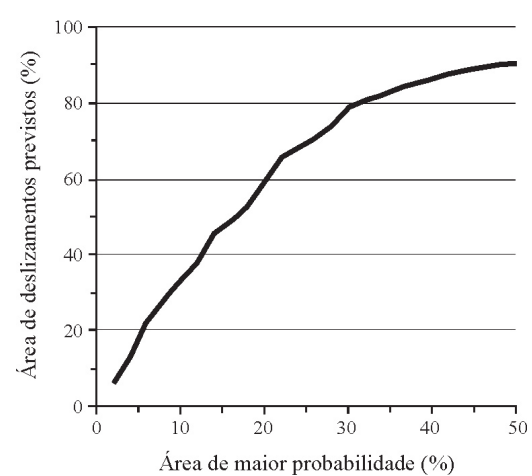

Fig. 17 - Área de deslizamentos previstos (taxa de predição) para os $50 \%$ de área com maior valor de probabilidade, baseada em metade dos eventos. Fig. 17 - Prediction-rate curve of susceptibility assessment for the $50 \%$ area with higher values of probability, based on $50 \%$ of landslide data set. 
superficiais. A subjectividade inerente aos métodos directos, em que a susceptibilidade é definida qualitativamente para um conjunto de unidades espaciais definidas à partida com base nas suas características físicas e humanas, é aqui substituída por uma metodologia baseada na análise estatística e probabilística. O cruzamento, no âmbito de um SIG, dos temas cartográficos que representam os factores condicionantes permite a geração automática de um conjunto alargado de unidades homogéneas, onde as classes das variáveis independentes possuem o mesmo valor. Neste caso concreto, a intersecção das cinco variáveis, assente numa estrutura de dados matricial, permitiu a definição de 77706 manchas correspondentes a 2133 (entre 9000 possíveis) unidades espaciais homogéneas. Cada uma destas unidades possui um mesmo valor de probabilidade, de acordo com um determinado modelo de susceptibilidade, e reflecte um conjunto de características físicas e humanas que a distingue das restantes.

Os resultados obtidos pelo modelo podem ser considerados bastante satisfatórios, visto que em apenas $1 / 3$ da área considerada mais susceptível pode ser encontrada cerca de $80 \%$ da área dos deslizamentos conhecidos. No entanto, existem alguns aspectos a ter em consideração na análise dos valores obtidos e em futuros desenvolvimentos da metodologia. Por um lado, existe ainda uma pequena fracção dos deslizamentos que não é correctamente prevista pelo modelo actual, situando-se em áreas onde os valores de susceptibilidade são baixos. Este facto dever-se-á, provavelmente, à não consideração de alguns factores que podem actuar como condicionantes relevantes em relação a um núcleo restrito de deslizamentos, como a acção dos cursos de água e a instabilização provocada pela construção de infra-estruturas humanas. Outras variáveis, como a forma das vertentes, poderão ainda contribuir para melhorar o desempenho do modelo. Por outro lado, o modelo baseia-se unicamente na análise bivariada entre os deslizamentos e os factores condicionantes, pelo que a relação de dependência entre estes factores não é considerada. Por último, os valores obtidos pelo modelo não devem ser considerados valores de probabilidade de ocorrência, visto que a componente temporal não é considerada. Definem, sim, a maior ou menor susceptibilidade de virem a ocorrer deslizamentos ao longo de um espaço de tempo indeterminado, ou seja, traduzem-se numa hierarquização da sensibilidade relativa de cada unidade de terreno relativamente à ocorrência deste tipo de fenómeno.

\section{AGRADECIMENTOS}

Este trabalho foi desenvolvido no âmbito do projecto europeu ALARM (Assessment of Landslide Risk and Mitigation in Mountain Areas, 2001-2003) e baseia-se numa base de dados cartográfica construída para o projecto europeu NEWTECH (New Technologies for Landslide Assessment and Management in Europe, 1996-1998). 


\section{BIBLIOGRAFIA}

Ayala-CARCEDo, F. J. (2000) - La ordenación del territorio en la prevención de catástrofes naturales y tecnológicas. Bases para un procedimiento técnico-administrativo de evaluatión de riesgos para la población. Boletín de la AGE, 30: 37-49.

Bolstad, P. V. and Stowe, T. (1994) - An evaluation of DEM accuracy: elevation, slope and aspect, Photogrammetric Engineering \& Remote Sensing, 60 (11): 1327-1332.

Carrara, A.; Cardinali, M.; Guzzetti, F. and Reichenbach, P. (1995) - GiS technology in mapping landslide hazard. In Carrara, A. and Guzzetti, F. (eds.) - Geographical Information Systems in Assessing Natural Hazards. Kluwer Academic Publishers, Dordrecht: 135-175.

Carrara, A.; Guzzetti, F.; Cardinali, M. and Reichenbach, P. (1998) - Current limitations in modelling landslide hazard. In Buccianti, A.; Nardi, G. and Potenza, R. (eds.) - Proceedings of IAMG'98: 195-203.

Chung, C. F. and FABBri, A. (1993) - The representation of geoscience information for data integration. Nonrenewable Resources, 2 (2): 122-138.

Ferreira, A.; Zêzere, J. L. et Rodrigues, M. L. (1987) - Instabilité des versants dans la région au Nord de Lisbonne. Essai de cartographie géomorphologique, Finisterra - Revista Portuguesa de Geografia, XXII (44), Lisboa: 227-246.

Guzzetti, F; Carrara, A.; Cardinali, M. and Reichenbach, P. (1999) - Landslide hazard evaluation: a review of current techniques and their application in a multi-scale study, Central Italy, Geomorphology, 31, Elsevier: 181-216.

Hansen, A. (1984) - Landslide hazard analysis. In Brunsden, D. and Prior, D.B. (eds.) - Slope Instability. John Wiley \& Sons, Chichester: 523-602.

Hutchinson, J. N. (1995) - Landslide hazard assessment, keynote paper. In BELL, D. H. (ed.) - Landslides, Proceedings of the 6th International Symposium on Landslides. Balkema, Rotterdam: 1805-1841.

Irigaray, C; Chacón, J. and Fernández, T. (1996) - Methodology for the analysis of landslide determinant factors by means of a GIS: Application to the Colmenar area (Malaga, Spain). In CHAcón, J.; Irigaray, C. and Fernández, T. (eds.) - Landslides. Balkema, Rotterdam: 163-172.

Luino, F. (1998) - Study on some villages damage by natural processes in NW Italy. In MoorE, D. and Hungr, O. (eds.) - Proceedings of $8^{\text {th }}$ International IAEG Congress. Vancouver, Canada. Balkema, Rotterdam: 1065-1070.

Monckton, C. G. (1994) - An investigation into the spatial structure of error in digital elevation data. In Worboys, M. F. (ed.) - Innovations in GIS 1. Taylor \& Francis, London: 201-211.

YIN, K. L. and YAN, T. Z. (1998) - Statistical prediction models for slope instability of metamorphosed rocks. In Bonnard, C. (ed.) - Landslides, Proceedings of the Fifth International Symposium on Landslides, vol. 2. Balkema, Rotterdam: 1269-1272.

ZÊzere, J. L. (1996) - Mass movements and geomorphological hazard assessment in the Trancão valley, between Bucelas and Tojal. In FErreira, A. B. and Vieira, G. T. (eds.) - Fifth European Intensive Course on Applied Geomorphology - Mediterranean and Urban Areas. Departamento de Geografia, Universidade de Lisboa: 101-105.

ZÊzere, J. L. (1997) - Movimentos de vertente e perigosidade geomorfológica na região a norte de Lisboa. Dissertação de Doutoramento, Universidade de Lisboa. 575 p.

ZÊzere, J. L. (2002) - Landslide susceptibility assessment considering landslide typology. A case study in the area north of Lisbon (Portugal). Natural Hazards and Earth System Sciences, vol. 2, 1/2, European Geophysical Society: 73-82. 